\title{
The Cdc42 GTPase-associated proteins Gic1 and Gic2 are required for polarized cell growth in Saccharomyces cerevisiae
}

\author{
Guang-Chao Chen, Yung-Jin Kim, ${ }^{1}$ and Clarence S.M. Chan ${ }^{2}$ \\ Department of Microbiology, The University of Texas, Austin, Texas 78712 USA
}

\begin{abstract}
BEM2 of Saccharomyces cerevisiae encodes a Rho-type GTPase-activating protein that is required for proper bud site selection at $26^{\circ} \mathrm{C}$ and for bud emergence at elevated temperatures. We show here that the temperature-sensitive growth phenotype of bem 2 mutant cells can be suppressed by increased dosage of the GIC 1 gene. The Gic1 protein, together with its structural homolog Gic2, are required for cell size and shape control, bud site selection, bud emergence, actin cytoskeletal organization, mitotic spindle orientation/ positioning and mating projection formation in response to mating pheromone. Each protein contains a CRIB (Cdc42/Rac-interactive binding) motif and each interacts in the two-hybrid assay with the GTP-bound form of the Rho-type Cdc42 GTPase, a key regulator of polarized growth in yeast. The CRIB motif of Gicl and the effector domain of Cdc42 are required for this association. Genetic experiments indicate that Gic1 and Gic2 play positive roles in the Cdc42 signal transduction pathway, probably as effectors of Cdc42. Subcellular localization studies with a functional green fluorescent protein-Gicl fusion protein indicate that this protein is concentrated at the incipient bud site of unbudded cells, at the bud tip and mother-bud neck of budded cells, and at cortical sites on large-budded cells that may delimit future bud sites in the two progeny cells. The ability of Gic1 to associate with Cdc42 is important for its function but is apparently not essential for its subcellular localization.
\end{abstract}

[Key Words: Cellular morphogenesis; cell polarity; GTPase; Cdc42; Bem2]

Received July 11, 1997; revised version accepted September 11, 1997.

Cell growth in the budding yeast Saccharomyces cerevisiae is a highly polarized process (for review, see Roemer et al. 1996). Initiation of vegetative growth involves the selection of a nonrandom bud site on the surface of the ellipsoidal cell (Chant and Pringle 1995). After bud emergence, growth occurs initially at or near the bud tip and then later throughout the bud, which becomes the daughter cell after cytokinesis. Under commonly used laboratory culture conditions, a or $\alpha$ haploid cells bud mostly from sites near the site of the previous cell division (i.e., axial fashion), whereas a/ $\alpha$ diploid cells bud in a bi polar fashion, with mother cells that have budded at least once budding from either pole and daughter cells that have never budded budding preferentially from the pole opposite the site of the previous cell division. In response to mating factor, haploid cells al so undergo polarized growth by the formation of mating projection. A number of proteins that are required for bud site selection or mating projection formation have been identified (for review, see Roemer et al. 1996).

\footnotetext{
${ }^{1}$ Present address: Department of Molecular Biology, Pusan National University, Pusan, 609-735, Korea.

${ }^{2}$ Corresponding author.

E-MAIL clarence chan@mail.utexas.edu; FAX (512) 471-7088.
}

Once a bud site has been selected, other proteins are required for the subsequent localization of growth to this site (i.e., bud emergence instead of isotropic growth). Of particular interest is the evolutionarily conserved, Rasrelated, Rho-type Cdc42 GTPase (Johnson and Pringle 1990), which cycles between the GDP-bound (presumably inactive) and the GTP-bound (presumably active) states. It is regulated by the Cdc24 GDP dissociation stimulator (Bender and Pringle 1989; Zheng et al. 1994; Ziman and Johnson 1994), the Bem3 and Rgal (Dbm1) GTPase-activating proteins (GAPs) (Zheng et al. 1993, 1994; Stevenson et al. 1995; Chen et al. 1996), and possibly the Zds1 and Zds2 proteins (Bi and Pringle 1996). Conditional cdc24 and cdc42 mutant cells are defective in bud emergence and local ized cell surface growth, and they become arrested as large, multinucleate, unbudded cells at the restrictive growth temperature (Sloat and Pringle 1978; Sloat et al. 1981; Adams and Pringle 1984; Adams et al. 1990). These cells are al so defective in their response to mating factor and thus cannot mate at the restrictive temperature (Simon et al. 1995; Zhao et al. 1995).

Genetic and biochemical studies indicate that Cdc42 and its regulators associate (directly or indirectly) and function together with the bud site selection proteins 
Bnil and Rsrl (Bud1), thus suggesting that the bud site selection proteins may recruit $\mathrm{Cdc} 42$ to selected bud sites, where Cdc42 can perform its function in bud emergence (Bender and Pringle 1989; Ruggieri et al. 1992; Peterson et al. 1994; Zheng et al. 1995; Evangelista et al. 1997; Park et al . 1997). Cdc42, like its mammalian counterparts, functions at least in part to regulate the actin cytoskeleton. cdc42 mutant cells are defective in the organization of the yeast actin cytoskeleton (Adams and Pringle 1984; Adams et al. 1990; Ziman et al. 1991), and the ability of permeabilized cdc42 mutant cells to assemble cortical actin patches in vitro is greatly reduced (Li et al . 1995). A functional actin cytoskel eton is important for polarized cell growth because it serves to target secretory vesicles to growth sites (Ayscough et al. 1997). How Cdc42 promotes polarized actin cytoskeletal assembly and bud emergence is unknown. A number of putative effectors of Cdc42 have been identified. Ste20, Cla4, and Skm1 (Cvrcková et al. 1995; Simon et al . 1995; Zhao et al. 1995; Martin et al. 1997) belong to the p21activated kinase (PAK) family of protein kinases. Ste20 and $\mathrm{Cla} 4$ are known to associate with GTP-bound Cdc42, and at least Ste20 becomes activated by this association. Boi 1 (and perhaps al so its structural homolog Boi2) also associates (directly or indirectly) with GTPbound $\mathrm{Cdc} 42$, but its biochemical properties are unknown (Bender et al. 1996; M atsui et al. 1996).

BEM 2 (IPL2) encodes a GAP predicted to be specific for Rho-type GTPases (Kim et al. 1994; Peterson et al . 1994). In vitro, the recombinant GAP domain of Bem2 stimulates the GTPase activity of Rhol, but not Cdc42 (Zheng et al. 1993, 1994; Peterson et al. 1994). However, the phenotypes of bem 2 mutant cells are more similar to those of cdc42 rather than rhol mutant cells (Bender and Pringle 1991; Chan and Botstein 1993; Kim et al. 1994; Peterson et al. 1994; Yamochi et al. 1994; Wang and Bretscher 1995). At permissive growth temperatures, conditional bem 2 mutants exhibit randomized bud site selection, whereas at restrictive growth temperatures, these mutants are defective in bud emergence and become arrested as large, round, multinucleate cells that are mostly unbudded. Furthermore, loss of Bem2 function can be compensated by specific alterations in the Rgal (Dbm1) GAP (Chen et al. 1996), which interacts physically with Cdc42 (and more weakly with Rhol) (Stevenson et al. 1995). These observations suggest that Bem2, like Cdc42, may serve to link proteins invol ved in bud site selection to those involved in bud emergence.

\section{Results}

Suppression of the bem2-101 mutation by increased dosage of GIC1 or its homolog GIC2

To identify gene products that function with the Bem2 Rho-type GAP in the regulation of cellular morphogenesis, we isolated yeast genes that in high copy number could suppress the temperature-sensitive (Ts $)$ growth defect of bem2-101 mutant cells (see Materials and Methods). One such gene, which we named GICl
(GTPase-interacting component 1, see below), will be the subject of this report. A high copy number GIC1 plasmid could suppress the Ts ${ }^{-}$phenotype of bem2-101 and bem 2 null mutant cells at 35 and $33^{\circ} \mathrm{C}$, respectively (data not shown). Furthermore, this plasmid could suppress weakly the randomized bud site selection defect of bem2-101 cells at $26^{\circ} \mathrm{C}$ (reducing the fraction of cells with randomized bud site selection pattern from $\sim 41 \%$ to $\sim 30 \%$ ). Subcloning and partial sequence analysis revealed that GIC 1 is allelic to the hypothetical open reading frame (ORF) YHR061c. GIC1 potentially encodes a protein of 314 residues, with a predicted molecular mass of $35 \mathrm{kD}$ (Fig. 1A).

A search of the compiled databases at the $\mathrm{N}$ ational Center for Biotechnology Information (NCBI) revealed that the Gicl protein is related in sequence to the putative gene product of the hypothetical yeast ORF YDR309c, which we have named GIC2. The Gic2 protein is predicted to contain 383 residues, with a molecular mass of $43 \mathrm{kD}$ (Fig. 1A). Over the entire length of the protein, Gicl displays 39\% identity and 54\% similarity to Gic2. Gicl and Gic2 are not significantly homologous to other known proteins. N orthern bl ot anal ysis revealed that GIC1 as well as GIC2 are expressed at similar levels in hapl oid ( $\mathbf{a}$ or $\alpha$ ) and di ploid ( $\mathbf{a} / \alpha)$ cells (data not shown). A high copy number GIC2 plasmid failed to suppress the Ts $^{-}$growth defect of bem2-101 mutant cells, although it, like a GIC 1 plasmid, could suppress weakly the bud site selection defect of bem2-101 cells at $26^{\circ} \mathrm{C}$ (reducing the fraction of cells with randomized bud site selection pattern from $\sim 41 \%$ to $~ 32 \%$ ). Thus, Gic1 and Gic2 have related, but perhaps not identical, functions in vivo.

Gic1, Gic2, and Bem2 together are essential for cell viability

To determine the importance of Gic1 and Gic2 for the normal growth of yeast cells, we examined the growth properties of cells lacking Gic1 and/or Gic2. Tetrad analysis of diploid yeast strains (CBY1830-51-1 or CBY 1830-51-2) that are heterozygous for the gic1 null (gic1- $\Delta 1:$ :LEU2) and the gic2 null (gic2-1::HIS3 or gic2$\Delta 2:: T R P 1$ ) mutations (see Materials and Methods) re vealed that haploid gicl and gic2 mutant cells are viable on YEPD-rich medium at temperatures ranging from 13 to $37^{\circ} \mathrm{C}$, and gic2 cells have a reduced growth rate at $37^{\circ} \mathrm{C}$. Furthermore, haploid gicl gic2 double mutant cells have normal growth rates at $26^{\circ} \mathrm{C}$ but are inviable at $\geqslant 33^{\circ} \mathrm{C}$ (Fig. 2A). The Ts $^{-}$phenotype of gicl gic2 cells, unlike that of bem2 cells, could not be rescued by the presence of an osmotic stabilizer (e.g., 1 м sorbitol; data not shown).

Further genetic analyses showed that the gic1, but not the gic2, mutation exacerbates slightly the $\mathrm{Ts}^{-}$phenotype caused by the bem 2 null mutation, and that gicl gic2 bem2 triple mutant cells are extremely slow growing at $26^{\circ} \mathrm{C}$, the permissive growth temperature for gicl gic2 double mutant and bem2 single mutant cells (Fig. 2B). This synthetic relationship between gicl, gic2, and bem 2 mutations is consistent with the observed sup- 


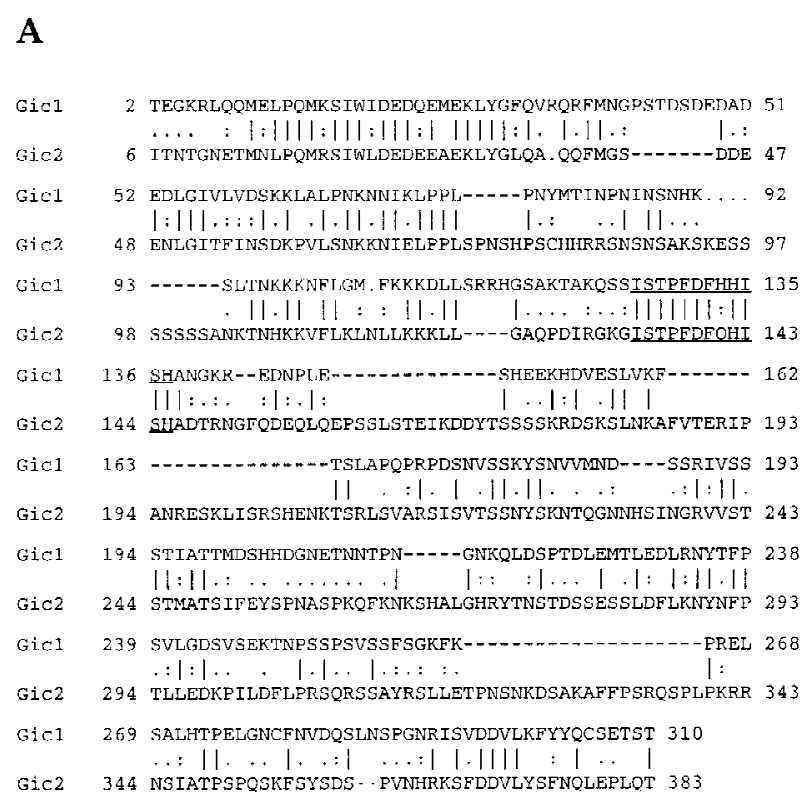

B

\begin{tabular}{lll} 
ACK & (human) & ISQPLQNSFIHTGH \\
MLK3 & (human) & ISMPLD--FKHRIT \\
MIHCK & (Dictyostelium) & VGSPFN--VKHNIH \\
$\alpha-$ PAK & (rat) & ISLPSD--FEHTIH \\
Ste20 & (yeast) & ISTPYN--AKHIHH \\
Cla4 & (yeast) & VSSPTN--FTHKVH \\
Skm1 & (yeast) & VSSPTN--FTHKVH \\
WASP & (human) & IGAPS--FKHVH \\
Gic2 & (yeast) & ISTPFD--FOHISH \\
Gic1 & (yeast) & ISTPFD--FHHISH \\
Gic1-2 & & \\
Gic1-3 & & ISTPFD--FHAISA \\
\hline
\end{tabular}

Figure 1. (A) Comparison of the predicted sequences of Gicl (GenBank accession no. U 00061) and Gic2 (GenBank accession no. U 28374). Gaps introduced for alignment purposes (dashes) as well as sequence identity (vertical lines) and similarity (periods and colons) are indicated. The CRIB motif present in each protein is underlined. (B) Sequence comparison of the CRIB motifs present in ACK (GenBank accession no. L13738), MLK3 (GenBank accession no. L32976), MIHCK (GenBank accession no. U 67716), $\alpha$-PAK (GenBank accession no. U 23443), Ste20 (GenBank accession no. L04655), Cla4 (GenBank accession no. X82499), Skm1 (GenBank accession no. X69322), WASP (GenBank accession no. U12707), Gic1, and Gic2. Sequences of the modified CRIB motif in mutant proteins Gic1-2 and Gicl-3 are also shown.

pression of the bem2-101 mutation by increased dosage of GIC1 and GIC2, and it indicated that Gic1, Gic2, and Bem2 together perform a function that is essential for yeast cell growth. Weal so examined the effect of increasing BEM 2 dosage in gic1 gic2 mutant cells. Our results showed that a high copy number BEM 2 plasmid cannot suppress the $\mathrm{Ts}^{-}$phenotype of gicl gic2 cells (Fig. 3A). Interestingly, a low copy number SSD1-v1 plasmid, which can suppress bem2 mutations (Kim et al. 1994), could suppress the Ts ${ }^{-}$phenotype of gicl gic2 cells. SSD 1 is a polymorphic gene of unknown function (Sutton et al. 1991). Different laboratory yeast strains contain either the SSD 1-v1 or the ssd1-d2 all el e. The yeast strains used in this study presumably contained the ssd1-d2 allele.

Gic1 and Gic2 together are required for proper bud site selection, bud emergence, and mitotic spindle orientation and positioning

To investigate whether Gic1 and Gic2, like Bem2, play important roles in cellular morphogenesis, we examined in greater detail the phenotype of haploid gic1, gic2, and gic1 gic2 mutant cells. At $26^{\circ} \mathrm{C}$, haploid gicl and gic2 single mutant cells had normal cell shape, budding pattern, mating efficiency, and actin cytoskel eton that was polarized (data not shown). Cells of a mating type formed mating projections in response to $\alpha$-factor with wild-type efficiency ( $\geqslant 90 \%$ of cells after 2 hr). After a 4-hr incubation at $37^{\circ} \mathrm{C}$, gic 1 and gic 2 mutant cells remained normal in shape and size, and they exhibited normal actin organization and budding pattern (data not shown).

In contrast, haploid gi cl gic2 double mutant cells were heterogeneous in shape and size at $26^{\circ} \mathrm{C}$, with many $(\leqslant 30 \%$ ) cells being rounder and somewhat enlarged (Fig. $4 d)$. These cells showed a moderate randomization of bud site sel ection, as indicated by an increase in the fraction of cells $(\sim 23 \%)$ that had a nonaxial budding pattern (Fig. 4f). The severity of this bud site selection defect was somewhat dependent on the genetic background of the

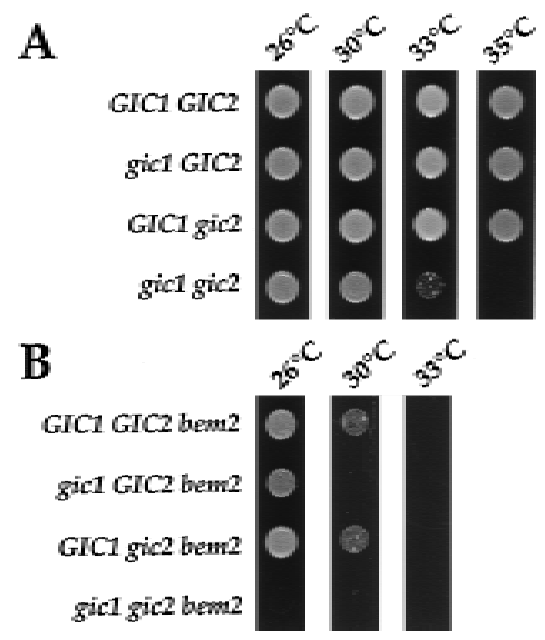

Figure 2. Synthetic growth phenotype caused by combinations of gicl, gic2, and bem2 mutations. Suspensions of yeast cells were spotted on YEPD plates and allowed to grow at the indicated temperatures for 2 days. The yeast strains used were (A) CCY311-17A (GIC1 GIC2), CCY1033-11B (gic1- $\Delta 1$ ::LEU 2 GIC2), CCY1033-5A (GIC1 gic2-1::HIS3), and CCY1033-5D (gic1- $\Delta 1:: L E U 2$ gic2-1::HIS3); and (B) CCY1030-11B (GIC1 GIC2 bem2- $\Delta 110:: T R P 1)$, CCY 1030-10C (gic1- $\Delta 1:$ :LEU 2 GIC2 bem2- $\Delta 110:: T R P 1)$, CCY1030-6D (GIC1 gic2-1::HIS3 bem2$\Delta 110:: T R P 1$ ), and CCY 1030-28D (gic1- $\Delta 1::$ LEU 2 gic2-1::HIS3 bem2- $110:: T R P 1)$. 

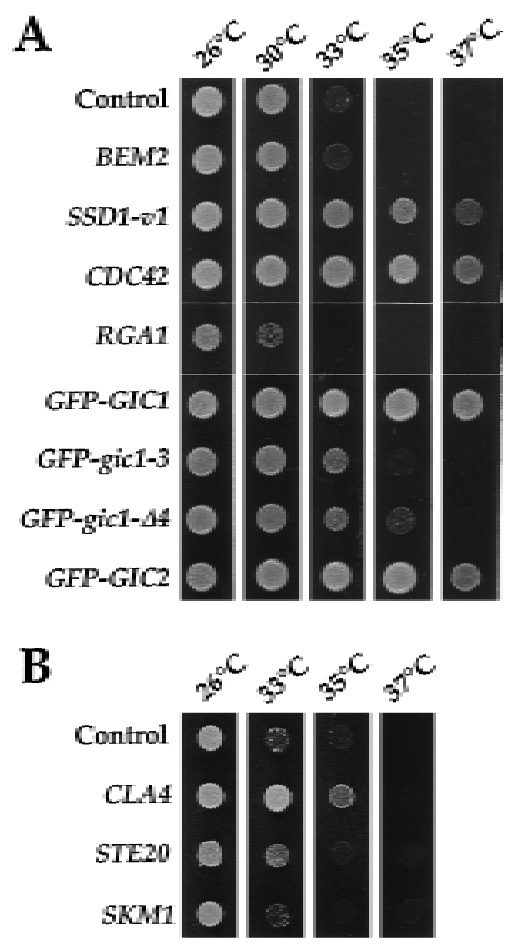

Figure 3. $\mathrm{Ts}^{-}$growth phenotype of a gicl gic2 mutant carrying different plasmids. Suspensions of gic1- $\Delta 1::$ LEU 2 gic2-1::HIS3 (CCY 1024-19C) mutant cells carrying different plasmids were spotted on YEPD (A) or supplemented SD lacking uracil (B) plates and allowed to grow at the indicated temperatures for 2 days. The plasmids used were high copy number control plasmid pSM217, BEM2-containing high copy number plasmid pCC251, SSD1-v1-containing low copy number plasmid pCC 75, CDC42-containing high copy number plasmid YEpUCDC42, RGA1-containing high copy number plasmid pC C693, GFP-GIC1-containing low copy number plasmid pCC995, GFP-gic1-3-containing low copy number plasmid pCC1051-1, GFP-gic1- $\Delta 4$-containing low copy number plasmid pCC1067-1, GFP-GIC2-containing low copy number plasmid pCC1065-1, CLA4-containing high copy number plasmid pCC1079, low copy number plasmid pVTU-STE20 that carries STE20 under the control of the ADH1 promoter, and SKM1-containing high copy number plasmid YEp352-SKM 1.

yeast strains tested (data not shown). Many of the larger gicl gic2 double mutant cells al so exhibited delocalized cell surface growth, as indicated by the presence of diffused chitin staining, which was not restricted to bud scars (Fig. 4f). The organization of the actin cytoskeleton was also somewhat perturbed in many of the larger gicl gic2 mutant cells, with the high concentration of cortical actin patches normally found at one end of some unbudded wild-type cells either missing or reduced (Fig. 4e). After a 2-hr exposure to $\alpha$-factor, $298 \%$ of gicl gic2 cells of a mating type became arrested as unbudded cells, but only $60-70 \%$ of these cells formed mating projections, suggesting that the round and enlarged cells are defective in mating projection formation. However, gic1 gic2 mutant cells mated with normal efficiency with

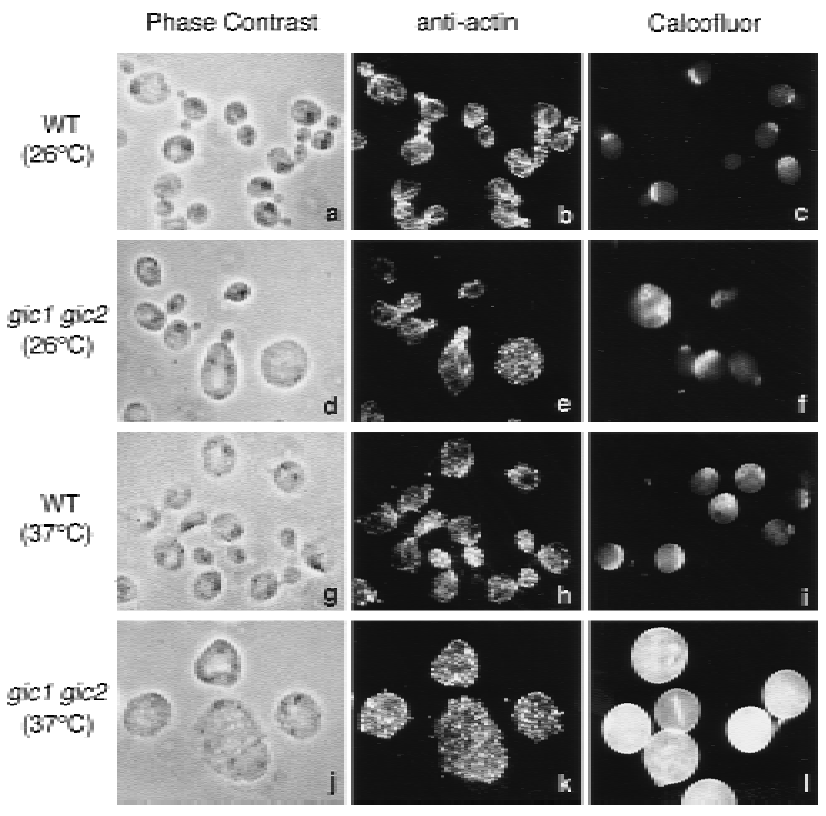

Figure 4. Cytological examination of wild-type and gicl gic2 mutant cells. Wild-type (CCY441-52D) (a-c and g-i) and gicl gic2 (CCY 1024-19C) (d-f and j-I) haploid cells grown at $26^{\circ} \mathrm{C}$ or at $37^{\circ} \mathrm{C}$ for $4 \mathrm{hr}$ were fixed and stained with Cal cofluor or antiactin antibodies. The phase and anti-actin staining images were obtained from the same cells. All cells are shown at the same magnification.

both wild-type and gicl gic2 mutant cells (data not shown).

DAPI staining showed that about one third of the larger gi c1 gic2 cells were multinucleate (Fig. 5j-I). Antitubulin staining revealed the presence of mitotic spindles in some enlarged, unbudded cells, suggesting

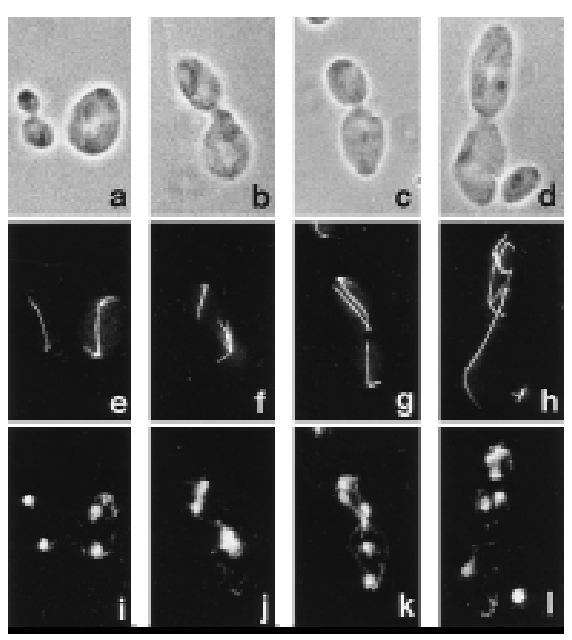

Figure 5. Abnormal mitotic spindle behavior of gicl gic2 mutant cells. gicl gic2 (CCY 1024-19C) hapl oid cells grown at $26^{\circ} \mathrm{C}$ were fixed and stained with DAPI or anti-tubulin antibodies. Phase (a-d), anti-tubulin staining (e-h), and DAPI-staining (i-l) images are shown. 
that these cells are defective in bud emergence even at $26^{\circ} \mathrm{C}$ (Fig. 5e). Mitotic spindles were misoriented in a small number of the budded cells (Fig. 5f,h). M ore frequently, the positioning of the spindles appeared abnormal, with spindles that lay entirely or mostly within the mother or the bud of large budded cells (Fig. 5f-h), indicating that nuclear migration occurred, but that this process might not be regulated properly. In a small fraction of cells with two or more mitotic spindles, the lengths of the spindles differed greatly (Fig. 5h), thus suggesting that the timing for the onset of anaphase or the rate of spindle el ongation is not coordinated between the multiple spindles within a single cell. We do not know whether this property is unique to gic1 gic2 cells, or whether it is common to other multinucl eate yeast cells. Because spindle defects were seen mostly in gic1 gic2 cells that were enlarged or round, they likely occurred as a consequence of the morphological defects observed in these cells. However, we cannot rule out the possibility that Gic1 and Gic2 play a more direct role in regulating spindle behavior. After a 4-hr incubation at $37^{\circ} \mathrm{C}, \sim 80 \%$ of gicl gic2 double mutant cells became arrested as unbudded cells that were mostly round and enlarged (see Fig. 4j). The actin cytoskeleton in these cells was no longer polarized (Fig. 4k), and they exhibited delocalized cell surface growth and chitin deposition (Fig. 4I). Thus, Gic1 and Gic2 play important roles in polarized growth and spindle behavior, especially at elevated temperatures.

\section{Gic1 and Gic2 can associate with the Cdc42 GTPase}

The phenotypes of gicl gic 2 mutant cells are similar in many respects to those exhibited by bem 2 and, interestingly, cdc42 mutant cells (Adams and Pringle 1984; Adams et al . 1990; Bender and Pringle 1991; Chan and Bostein 1993; Kim et al. 1994; Peterson et al. 1994; Wang and Brescher 1995). Examination of the Gicl and Gic2 sequences reveal ed that each protein contains a Cdc42/ Rac-interactive binding (CRIB) motif (see Fig. 1A,B), which is present in a number of proteins that bind the GTP-bound form of the Rho-type Cdc42 and Rac GTPases (Burbelo et al. 1995). We used the two-hybrid assay (Finey and Brent 1994) to investi gate whether Gicl or Gic2 physically interacts in vivo with known yeast Rho-type GTPases, specifically Cdc42, Rho1, Rho2, Rho3, and Rho4 (Simon et al. 1995). Our results showed that fusion proteins with the B42 transactivation domain (AD) fused to full-length Gic1 or Gic2 (Gyuris et al. 1993) interact specifically with LexA-Cdc42 (which was nonprenylated as a result of the $\mathrm{C} 188 \mathrm{~S}$ mutation) but not the other GTPase fusion proteins tested (Fig. 6). This interaction required an intact effector domain of LexACdc42, which was altered by the T35A mutation (Ziman et al. 1991). Interaction was specific for the GTP-bound form of LexA-C dc42 (G12V or Q 61L); no interaction was detected with mutant LexA-Cdc42 (D118A) that was trapped in the GDP-bound state.

To find out whether the CRIB motif present on Gicl is required for the association between $\mathrm{Gicl}$ and $\mathrm{Cdc42}$, we

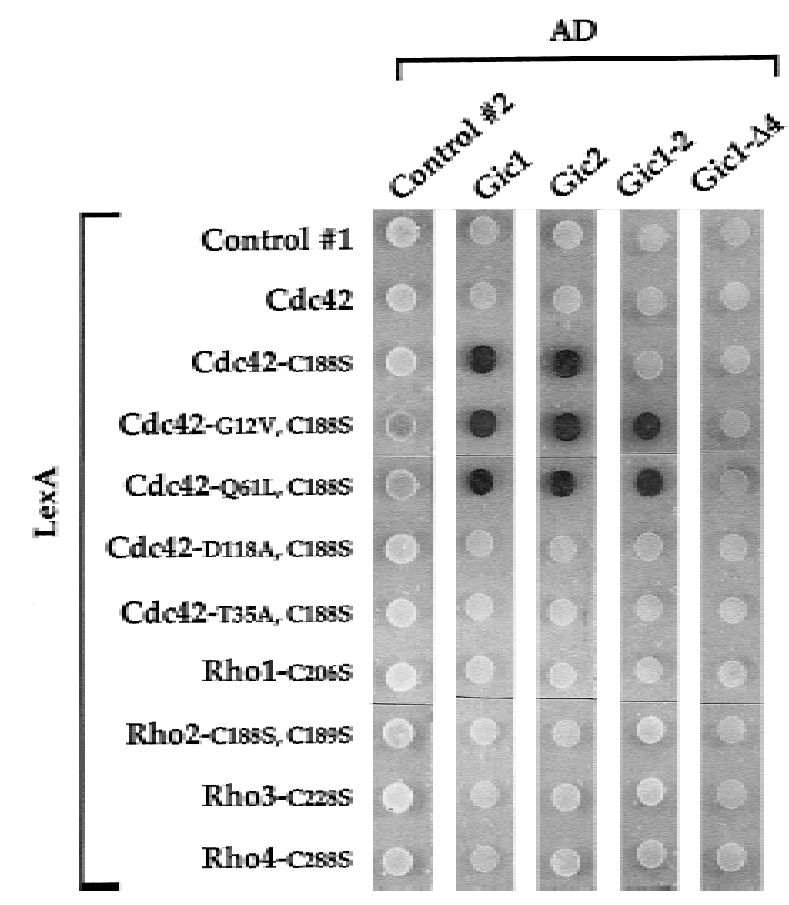

Figure 6. CRIB motif-dependent interaction of Gicl and Gic2 with GTP-bound Cdc42 in the two-hybrid assay. Suspensions of diploid yeast cells (EGY 48 [pSH 18-34] × RFY206) containing combinations of the following plasmids were spotted on SGal/Raf/XGal plates and were allowed to grow at $30^{\circ} \mathrm{C}$ for 4 days. Blue color (seen here as dark color) indicates a specific interaction in the two-hybrid assay. The plasmids used were pEG202 (Control \#1), pEG202-CDC42 (Cdc42), pEG202$\mathrm{CDC}_{2}{ }^{\mathrm{C} 188 \mathrm{~S}}$ (Cdc42-C 188S), pEG202-CDC42 ${ }^{\mathrm{G} 12 \mathrm{~V}, \mathrm{C} 188 \mathrm{~S}}$ (Cdc42-

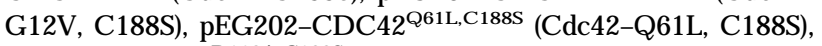
pEG202-CDC42 ${ }^{\mathrm{D} 118 \mathrm{~A}, \mathrm{C} 188 \mathrm{~S}}$ (Cdc42-D118A, C188S), pCC10812 (Cdc42-T35A, C188S), pEG202-RHO1 C206S (Rho1-C206S), pEG202-RHO2 ${ }^{\text {C188S,C189S }}$ (Rho2-C188S, C189S), pEG202$\mathrm{RHO}^{\mathrm{C} 228 \mathrm{~S}}$ (Rho3-C228S), pEG202-RHO4 ${ }^{\mathrm{C} 288 \mathrm{~S}}$ (Rho4-C288S), pJ G4-5 (Control \#2), pCC984 (Gic1), pCC985 (Gic2), pCC1044-1 (Gicl-2), and pCC1066-1 (Gicl- $\Delta 4)$.

generated mutant AD-Gicl that had two (AD-Gic1-2) or four (AD-Gicl-3) of the conserved residues within the CRIB motif substituted by al anine (see Fig. 1B), as well as mutant $A D-G i c 1$ that lacked the 12 residues that define the CRIB motif (AD-Gicl- $\Delta 4$ ). Interaction was still detected, al though at a reduced level, between AD-Gic1-2 and GTP-bound forms of LexA-Cdc42. No interaction was detected between AD-Gicl-3 or AD-Gicl- $\Delta 4$ and any form of LexA-C dc42 tested (Fig. 6; data not shown). These results indi cated that the interaction of Gicl with Cdc42 requires its CRIB motif, and that at least one of the two conserved histidine residues of the CRIB motif in Gicl is important, although not absolutely essential, for the function of this motif.

Genetic interactions between GIC1, GIC2, and CDC42

To find out more about the functional relationship between Gic1, Gic2, and Cdc42, we examined possible ge- 
netic interactions between GIC1, GIC2, CDC42, CDC 24, and RGA 1. CDC24 encodes the GDP dissociation stimulator (and thus positive regulator) for $\mathrm{Cdc} 42$ (Zheng et al. 1994), whereas RGAl encodes a putative GAP that associates with $\mathrm{Cdc} 42$ and functions as its negative regulator in vivo (Stevenson et al . 1995; Chen et al. 1996). Our results showed that the gic2 mutation exacerbates the $\mathrm{Ts}^{-}$phenotype caused by the cdc42-1 and cdc24-2 mutations (Fig. 7). Furthermore, gic1 gic2 cdc42-1 triple mutant cells were extremely sl ow growing at $26^{\circ} \mathrm{C}$, the permissive growth temperature for cdc42-1 and gicl gic2 mutant cells (Figs. 2 and 7), and gicl gic2 cdc24-2 triple mutant cells were sl ow growing at $30^{\circ} \mathrm{C}$, the permissive growth temperature for cdc24-2 and gicl gic2 mutant cells (Figs. 2 and 7). In addition, a high copy number CDC 42 plasmid, but not a similar CDC 24 plasmid, could complement the $\mathrm{Ts}^{-}$phenotype of gicl gic2 mutant cells at $37^{\circ} \mathrm{C}$ (see Fig. $3 \mathrm{~A}$; data not shown). This effect was specific to CDC 42, as similar plasmids carry-

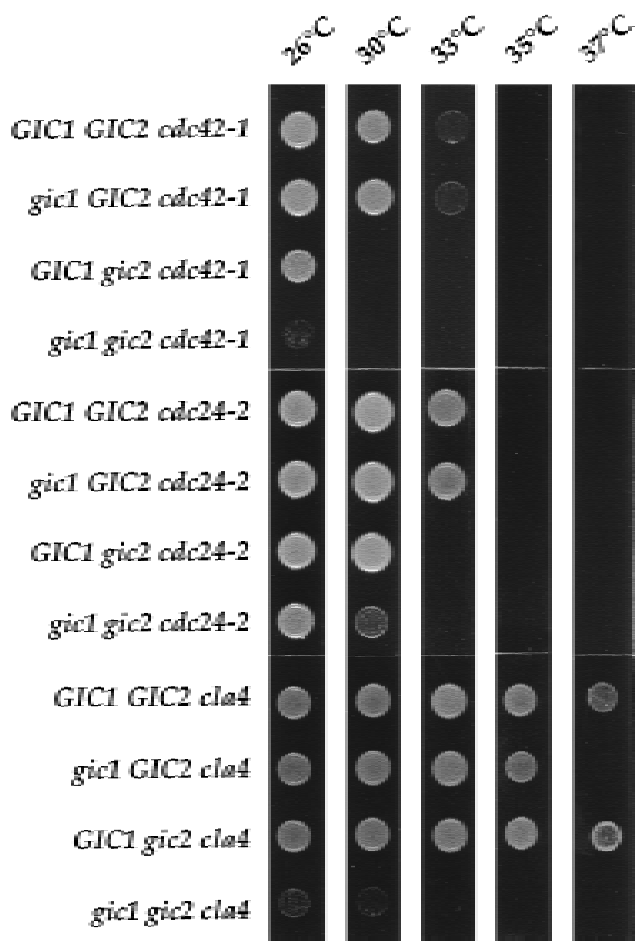

Figure 7. Exacerbation of the growth defect of gic1, gic2, and gic1 gic2 cells by cdc24, cdc42, and cla4 mutations. Suspensions of yeast cells were spotted on YEPD plates and allowed to grow at the indicated temperatures for 2 days. The yeast strains used were CCY896-8B (GIC1 GIC2 cdc42-1), CCY1027-24A (gic1- $\Delta 1$ ::LEU2 GIC2 cdc42-1), CCY1027-6A (GIC1 gic21::HIS3 cdc42-1), CCY1027-11D (gic1- $\Delta 1:$ LEU 2 gic2-1::HIS3 cdc42-1), CCY1032-16B (GIC1 GIC2 cdc24-2), CCY1032-6B (gic1- $\Delta 1:: L E U 2$ GIC2 cdc24-2), CCY1032-3A (GIC1 gic21::HIS3 cdc24-2), CCY1032-2B (gic1- $\Delta 1:$ LEU 2 gic2-1::HIS3 cdc24-2), CCY 1056-6A (GIC1 GIC2 cla4- $101:$ :URA3), CCY 1055-16C (gic1- $\Delta 1:: L E U 2$ GIC2 cla4- $\Delta 101:: U R A 3)$, CCY1055-12B (GIC1 gic2-1::HIS3 cla4- $101:: U R A 3)$, and CCY 1055-4C (gic1- $\Delta 1:$ :LEU 2 gic2-1::HIS3 cla4- $\Delta 101::$ U RA3). ing $\mathrm{RHO} 1, \mathrm{RHO} 2, \mathrm{RHO} 3$, or RHO 4 could not complement gicl gic2 mutant cells (data not shown). In contrast, a high copy number RGA 1 pl asmid exacerbated the $\mathrm{Ts}^{-}$phenotype of gicl gic2 mutant cells at $30^{\circ} \mathrm{C}$ (see Fig. $3 A$ ). These genetic results, together with the two-hybrid assay results described above, suggested that Gicl and Gic2 play a positive role in the Cdc42 pathway through their interaction with Cdc42.

Genetic interactions between GIC1, GIC2, and CLA4

Because increased dosage of CDC 42 could suppress the loss of GIC1 and GIC2, Cdc42 may act downstream of Gicl and Gic2. Alternatively, Gicl and Gic2 may act as downstream effectors of $\mathrm{Cdc} 42$, with some function of Gic1 and Gic2 shared by other effectors of Cdc42, perhaps Ste20 (Simon et al. 1995; Zhao et al. 1995), Cla4 (Cvrcková et al. 1995), or Skml (Martin et al. 1997). To explore this latter possibility, we examined the genetic relationship between GIC1, GIC2, STE20, CLA4, and SKM1. Our results showed that the ste20 and skm1 mutations did not significantly affect the growth phenotype of gicl, gic2, or gicl gic2 mutant cells (data not shown). In contrast, the cla4 mutation often caused gicl mutant cells to be $\mathrm{Ts}^{-}$at $37^{\circ} \mathrm{C}$, and gicl gic2 cla4 triple mutant cells were very slow growing at $26^{\circ} \mathrm{C}$, the permissive growth temperature for cla4 and gicl gic2 cells (Figs. 2 and 7). Furthermore, overexpression of CLA4, but not STE20 or SKM1, could complement partially the $\mathrm{Ts}^{-}$ phenotype of gicl gic 2 mutant cells at $35^{\circ} \mathrm{C}$ (see Fig. 3B). These genetic results suggested that Gic1, Gic2, and $\mathrm{Cla} 4$ function together as effectors of Cdc42 and that together they perform functions essential for polarized cell growth.

\section{Subcellular localization of Gicl}

To determine the subcellular localization of Gicl and Gic2, we generated fusi on genes encoding the green fluorescent protein (GFP) fused to full-length Gicl or Gic2 (Heim et al. 1995). The GFP-GIC1 and GFP-GIC2 fusion genes, which were under the control of the ACT1 promoter, were functional, as a low copy number plasmid encoding GFP-Gic1 or GFP-Gic2 could complement the $\mathrm{Ts}^{-}$phenotype of gicl gic2 mutant cells at $37^{\circ} \mathrm{C}$ (see Fig. 3A). The fluorescence signal of GFP-Gic2-expressing cells was weaker. Thus, we have concentrated on the study of GFP-Gicl. This fusion protein was present throughout the cytoplasm of diploid cells that expressed this protein. Approximately $45 \%$ of these cells had additional GFP-Gicl that was detected as one or more patches at the cell periphery (cortical) and $\sim 13 \%$ had a narrow band of GFP-Gicl at the mother-bud neck. In a minor fraction of these cells, GFP-Gicl was al so slightly enriched in the nucleus. The localization pattern of GFP-Gicl likely reflects that of endogenous Gicl because the fluorescence signal of GFP-Gicl at cortical sites and at the mother-bud neck was stronger in gicl null mutant cells than in wild-type cells (data not 
shown), suggesting that GFP-Gicl competes with endogenous Gicl for common binding sites.

In unbudded diploid cells, cortical GFP-Gicl was detected mostly $(\sim 93 \%)$ as a single patch at one pole of the cell (Figs. 8a and 9, class a) and less frequently ( $7 \%$ ) as two patches (which sometimes differed in intensity) at both poles (Figs. 8b and 9, class b). In cel Is with small- to medium-sized buds, cortical GFP-Gicl was detected almost exclusively as a single patch (which might be quite diffuse and in the shape of a crescent) at thetip of the bud (Figs. 8c-e and 9, classes d,e). These observations suggested that one of the two patches of GFP-Gicl seen in some unbudded cells disappears before bud emergence, and that the remaining patch is located at the incipient bud site. In large-budded dipl oid cells, cortical GFP-Gicl was most frequently detected as a patch at the tip of the bud (Figs. 8g,h,i,l, m and 9, classes k,l,n-p). Interestingly, many large budded cells, including those that had GFPGicl at their bud tips, al so had a patch of GFP-Gicl that was most frequently located either at the tip of the mother (Figs. 81,m and 9, classes $\mathrm{n}, \mathrm{o}$ ) or at the motherside of the mother-bud neck (Figs. 8k,n and 9, classes $p-r, t)$. Ninety-nine percent of such cells $(n=100)$ had fully separated chromatin masses (Fig. 8n,o), suggesting that this patch of GFP-Gicl first appears during telophase or early $\mathrm{G}_{1}$.

In some cells with medium- to large-sized buds, including those that had cortical GFP-Gicl, the fusion protein was also detected as a narrow band (or occasionally as two closely apposed bands) at the mother-bud neck (Figs. 8f,g,i,j,I and 9, classes e,f,I,m,o,r). Approximately $31 \%$ of these cells $(n=100)$ had unseparated chromatin masses, including some $(\sim 6 \%)$ that had the nucleus lo- cated away from the mother-bud neck. These observations suggested that GFP-Gic1 becomes localized to the mother-bud neck before the onset of anaphase and it persists at this site through tel ophase. The presence of largebudded cells with GFP-Gicl at either (or both) pole as well as at the mother-bud neck (Fig. 9, classes I,0) suggested that these cells give rise after cytokinesis to unbudded cells with cortical GFP-Gicl at both poles (Fig. 9, class b). Alternatively, in a bipolar budding diploid cell, GFP-Gic1 may localize to an incipient bud site that is located distal to the site of cytokinesis before the disappearance of GFP-Gicl from this latter site.

\section{Effect of bud site selection on Gicl localization}

The positions of cortical GFP-Gicl in large-budded diploid cells suggested that they are located at sites used for budding by the progeny cells after cytokinesis, with one cell budding from either pole, and the other budding preferentially from the pole opposite the site of the previous cell division. Thus, we also examined the localization pattern of GFP-Gicl in wild-type a haploid cells, which bud mostly from a site near the site of the previous cell division. As expected, GFP-Gicl was restricted to only one pole of unbudded cells (Fig. 9, class a) and it was absent from the mother tip of large-budded haploid cells (Fig. 9, classes n,o). Furthermore, it was often present at cortical sites located adjacent to the mother-bud neck (Figs. 8p,q,r, and 9, classes g,p-u). However, this fusion protein was still present at the tip of some buds (Fig. 9, classes d,e,k,l,p). The observation that large-budded haploid cells with cortical GFP-Gicl at both the bud tip and at other cortical sites were rarely seen suggested that
Figure 8. Subcellular localization of GFP-Gic1 and GFP-Gic1- $\Delta 4$. Subcellular localization of GFPGicl (a-n and p-u), GFP-Gicl- $\Delta 4(v-x)$, and DNA $(0, y)$ in wild-type diploid (DBY 1830) (a-o and v-y), wild-type haploid (CCY766-9D) (p-r), and bud5 hapl oid (CCY 404-2D) (s-u) cells. The DAPI-stained images of DNA shown in o and y were obtained from the cells shown in $n$ and $x$, respectively. (w) An enlarged view of the cell shown in v.
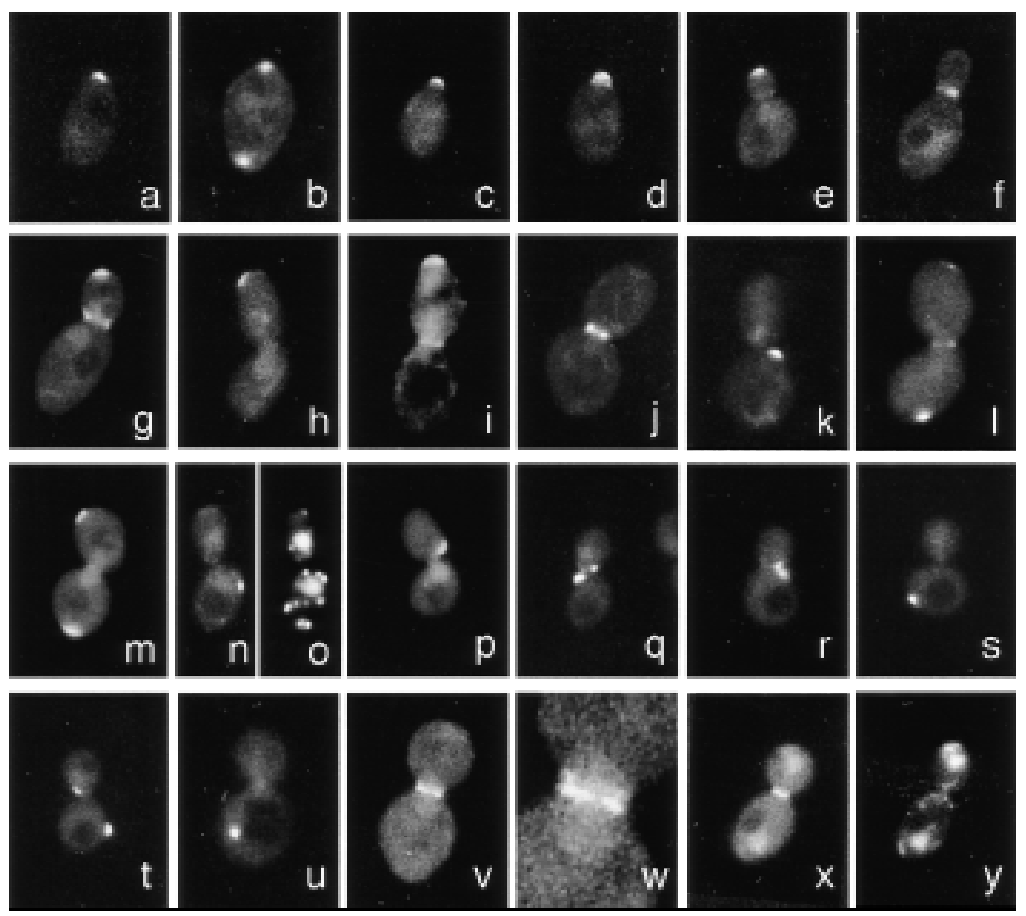


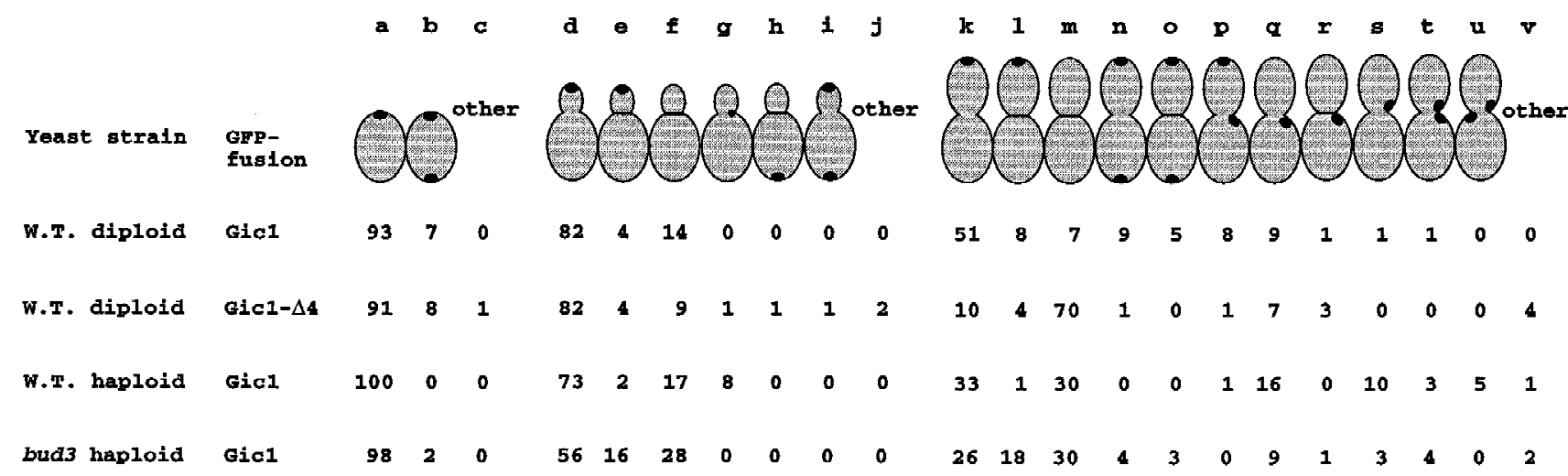

Figure 9. Summary of subcellular localization of GFP-Gicl and GFP-Gicl- $\Delta 4$. Y east cells carrying low copy number plasmids that encode GFP-Gicl or GFP-Gicl- $\Delta 4$ were grown in supplemented SD lacking uracil (with selection for U RA3 present on the different plasmids) at $\sim 24^{\circ} \mathrm{C}$ to a density of $\sim 5 \times 10^{6} \mathrm{cell} / \mathrm{s} / \mathrm{ml}$. The local ization of the GFP fusion protein was examined in cells at different stages of the cell cycle: U nbudded (a-c), small-to medium-budded ( $d-j$ ), and large-budded ( $k-v)$. The length of the bud in medium-budded cells is less than half the length of the mother cell. For each sample, $\geqslant 300$ cells that showed cortical or bud neck localization of GFP fusion protein were scored. The percentage of cells at each stage that showed the different localization patterns is shown. The nuclear Iocalization of GFP fusion protein present in some cells is not shown. The yeast strains used were DBY 1830 (wild-type diploid), CCY766-9D (wild-type haploid), and CCY1048-11A (bud3 haploid). The plasmids used were pCC995 (GFP-Gic1) and pCC1067-1 (GFP-Gic1- $\Delta 4)$.

GFP-Gicl mostly disappears from the bud tip before it reappears during tel ophase or early $\mathrm{G}_{1}$ (see above) at cortical sites that are used for budding after cytokinesis. We have al so examined the local ization of GFP-Gicl in haploid a cells that had been exposed to mating pheromone. In such cells, GFP-Gicl was found mostly in a single patch at or near the tip of mating projections (data not shown).

To confirm that the observed differences in the pattern of GFP-Gicl localization in hapl oid and dipl oid cells was indeed attributable to differences in bud site selection (i.e., axial vs. bipolar) and not attributable to differences in cell type (i.e., a vs. $\mathbf{a} / \alpha$ ) or ploidy, we examined the localization pattern of GFP-Gicl in a bud3 and bud5 mutant haploid cells, which have a bipolar (i.e., like wild-type $\mathbf{a} / \alpha$ diploid cells) and a randomized bud site selection pattern, respectively (Chant and Herskowitz 1991; Chant et al. 1991, 1995). Our results showed that the localization pattern of GFP-Gic1 in bud3 haploid cells was similar to that observed in wild-type diploid cells (Fig. 9). The observation that GFP-Gicl was detected at cortical sites located on the bud-side of the mother-bud neck at a slightly higher frequency in bud3 hapl oid than in wild-type diploid cells (Fig. 9, classes s,t) was probably attributable to the fact that, although diploid daughter cells are biased toward budding from the pole opposite the site of the previous cell division, the strength of this bias varies from strain to strain (Chant and Pringle 1995). In bud5 haploid cel Is, which often bud from the lateral side and not from the poles of the ellipsoi dal cell, cortical GFP-Gicl was detected on the side of $\sim 16 \%$ of large-budded cells (Fig. 8s,t). These results indicated that GFP-Gicl localizes to the inci pient bud site of unbudded cells, to the tip of budded cells where it persists for part of the period of bud growth, and to the mother-bud neck of cells with medium- to large-size buds. In addition, it localizes in large-budded cells to sites that are used for budding by the two progeny cells in the subsequent cell cycle.

\section{Effect of CRIB motif mutation on Gicl localization}

To find out whether the localization of GFP-Gicl is dependent on its association with $\mathrm{Cdc} 42$, we examined the localization of GFP-Gicl- $\Delta 4$, which lacks the 12 residues that define the CRIB motif of Gicl (see Fig. 1B). This protein was expected not to bind $\mathrm{Cdc} 42$ in vivo because AD-Gic1- $\Delta 4$ did not associate with LexACdc42 in the two-hybrid assay (see Fig. 6). Consistent with this prediction, GFP-gicl- $\Delta 4$, unlike GFP-GICl, was unable to complement the $\mathrm{Ts}^{-}$phenotype of gicl gic2 mutant cells at $37^{\circ} \mathrm{C}$ (see Fig. $3 \mathrm{~A}$ ), al though GFPGicl- $\Delta 4$ was present in somewhat higher abundance than GFP-Gicl (data not shown).

Our cytological studies revealed interesting differences between the local ization patterns of GFP-Gicl and GFP-Gic1- $\Delta 4$ in wild-type diploid cells. First, the abundance of GFP-Gicl- $\Delta 4$ present at the bud neck was slightly reduced, but a slightly increased fraction $(\sim 16 \%)$ of cells that expressed GFP-Gicl- $\Delta 4$ had this protein local ized to the bud neck (Fig. 9,e,f,h,l,m,o,r). [The apparent large increase in the fraction of large-budded cells with GFP-Gicl- $\Delta 4$ at the bud neck was attributable to the decrease in the fraction of cells with this protein at cortical sites (see below).] Second, an increased fraction $(\sim 10 \%)$ of large-budded cells that had GFP-Gicl- $\Delta 4$ at the bud neck contained a doublet (instead of a singlet) of bands at this site (Fig. 8v,w). Third, although GFP-Gicl$\Delta 4$ was still present at cortical sites, its abundance was reduced. This reduction might account at least partly for 
the smaller fraction ( 27\%) of GFP-Gic1- $\Delta 4$-expressing cells that had this fusion protein detected at cortical sites as well as the increased cytoplasmic fluorescence signal (Fig. 8v,x). Fourth, the abundance of GFP-Gicl- $\Delta 4$ present in the nucleus was greatly increased (Fig. 8x,y), and $\sim 18 \%$ of GFP-Gic1- $\Delta 4$-expressing cells had this fusion protein detected in the nucleus. Similar results were obtained for the localization of GFP-Gic1-3 (see Fig. 1B) in wild-type cells or GFP-Gicl- $\Delta 4$ in gicl- or gicl gic2null mutant cells (data not shown), thus arguing that the localization pattern of GFP-Gicl- $\Delta 4$ was not attributable to its possible misfolding caused by the 12-amino acid deletion or to its oligomerization with wild-type Gicl or Gic2.

These results indicated that (1) the localization of GFP-Gicl to the bud neck is mostly independent of its ability to associate with $\mathrm{Cdc} 42$, but the exact pattern of localization at this site is affected by this function of GFP-Gicl; and (2) the ability of GFP-Gicl to associate with Cdc42 is important, but not absolutely essential, for its localization to cortical sites. These results also suggested that GFP-Gicl- $\Delta 4$ may not be totally nonfunctional. GFP-gicl- $\Delta 4$ could complement partially the Ts phenotype of gicl gic2 mutant cells at $35^{\circ} \mathrm{C}$ and the cell size and shape control defect of these cells at $26^{\circ} \mathrm{C}$ (see Fig. 3A; data not shown).

\section{Discussion}

Gic1 and Gic2 as putative effectors of Cdc42

In this report, we describe GIC1, a novel gene identified as a dosage-dependent suppressor of bem2, and its structural and functional homolog GIC2 (Fig. 1). Gic1 and Gic2 together are required for cell viability at elevated temperatures (Fig. 2). In the two-hybrid assay, Gicl and Gic2 associate with the GTP-bound but not the GDPbound form of Cdc42 (Fig. 6). This association is dependent on the effector domain of Cdc42 and the CRIB motif of Gic1 (and probably Gic2). Because the Ts $\mathrm{s}^{-}$phenotype of gicl gic2 mutant cells is exacerbated by perturbations (e.g., the cdc42-1 and cdc24-2 mutations, or increased dosage of RGA1) that reduce Cdc42 function (Figs. 3A and 7), Gic1 and Gic2 must play a positive role in the Cdc42 signal transduction pathway, most probably as effectors of Cdc42, although we cannot rule out the possibility that they may al so function as posi tive regulators of Cdc42. Consistent with the observed genetic and physical interactions, gicl gic2 mutant cells, like cdc42 mutant cells, are defective in bud site sel ection, organization of the actin cytoskeleton, polarized cell surface growth, bud emergence, and mating projection formation (Fig. 4). If Gicl and Gic2 are effectors of Cdc42, their functions are probably shared by at least one other effector protein. This is because gicl gic 2 null mutant cells are viable at $26^{\circ} \mathrm{C}$, whereas cdc 42 null mutant cells are inviable at this temperature (Johnson and Pringle 1990). Furthermore, the $\mathrm{Ts}^{-}$phenotype of gicl gic2 mutant cells can be suppressed by an increase in the dosage of CDC 42 (Fig. 3A). This other effector protein may be the
Cla4 protein kinase, as gicl gic2 cla4 null mutant cells are very slow growing at $26^{\circ} \mathrm{C}$ (Fig. 7), and an increase in the dosage of CLA4 can suppress partially the Ts ${ }^{-}$phenotype of gicl gic2 cells (Fig. 3B). Cla4, like Gicl and Gic2, associates with the GTP-bound form of C dc42, and it is known to be required for efficient cytokinesis and proper control of polarized cell surface growth (Benton et al. 1993; Cvrcková et al. 1995).

\section{The subcellular localization and function of Gicl}

Polarized vegetative growth of yeast cells is thought to involve cortical positional signals that recruit polarity establishment proteins such as Cdc42 to incipient bud sites, where such proteins function in the process of bud emergence (for review, see Roemer et al. 1996). In haploid cells that bud axially, the positional signal is thought to be located transiently at the site of cytokinesis, where it serves after cell division as a template for the assembly of an adjacent positional signal that is used for budding. A number of proteins have been local ized to the site of cytokinesis, and they may function as part of the axial budding positional signal (for review, see Roemer et al. 1996). In diploid cells that bud bipolarly, the positional signal is thought to be located at both poles of an unbudded cell. The nature of the bipolar budding positional signal is less understood because until recently no protein had been local ized to the pole distal to the site of cytokinesis in mother cells.

Our localization study of GFP-Gicl (and presumably Gic1) has provided important insights into the problem of bud site selection and its connection to bud emergence (Figs. 8 and 9). In large-budded cel Is that have completed chromosome segregation, GFP-Gicl can be detected at cortical sites that are located at the poles or adjacent to the mother-bud neck. Examination of the location of these cortical sites in cells with different bud site selection patterns suggests that they are located at incipient bud sites for the progeny cells. Our preliminary results with time-lapse microscopy are consistent with this assignment (G. Chen and C. Chan, unpubl.). These observations show that bud site sel ection does not occur after cell division as proposed previously (for review, see Roemer et al. 1996). Instead, it may occur during telophase of the previous cell cycle or during early $G_{1}$ just before cytokinesis and cell separation. To our knowledge, the appearance of GFP-Gicl at the incipient bud site precedes that of all but one known protein. Aip3 (Bud6), which is needed for the bipolar budding pattern (Zahner et al. 1996), has also been local ized to incipient bud sites present on the mother-side of large-budded cells (Amberg et al. 1997). However, Aip3 differs from GFP-Gicl in that it is not localized to incipient bud sites that are present on the bud side of large-budded cells. In spite of the strategic localization of GFP-Gicl to incipient bud sites in both axial and bipolar budding cells, gicl gic2 mutant cells have relatively moderate bud site selection defects. This suggests that in the absence of Gicl and Gic2, other proteins that constitute the axial and 
bipolar specific positional signals can still be localized properly.

After cytokinesis, GFP-Gicl appears to remain at the incipient bud site of unbudded cells, where it presumably interacts with Cdc42 to carry out the process of bud emergence. GFP-Gicl persists at the bud tip of small- to large-budded cells. Cortical actin structures are known to be concentrated at incipient bud sites of unbudded cells and at the tip of small-budded cells (Kilmartin and Adams 1984). Because the concentration of cortical actin structures at incipient bud sites becomes less pronounced in unbudded gicl gic2 mutant cells that are enlarged, Gic1 (and Gic2) may play a role in organizing the cortical actin structures at this location, thus directly controlling bud emergence and growth. Interestingly, GFP-Gicl seems to disappear from the bud tip in large-budded cells. The exact timing of this disappearance is not known, but it probably occurs before or during telophase, when it relocalizes to incipient bud sites (including those located at the bud tip). The activation and inactivation of the $\mathrm{Cdc} 28 /$ mitotic cyclin complex during $\mathrm{G}_{2} / \mathrm{M}$ phase is known to control the redistribution of cortical actin structures from the bud tip to the entire bud and then to the bud neck (Lew and Reed 1993). It remains to be determined whether the disappearance of GFP-Gicl from the bud tip and its reappearance at incipient bud sites is similarly controlled.

GFP-Gicl is also present in a band (or two closely apposed bands) that spans the mother-bud neck of cells with medium- to large-sized buds. Upon cytokinesis, this band may give rise to a patch of GFP-Gicl that probably disappears before the next round of budding. The functional role of Gicl at the mother-bud neck is unknown. The localization of GFP-Gicl at this site is not required for its local ization to adjacent incipient bud sites, and gicl gic2 cells do not have noticeable cytokinesis defects. However, the gicl gic2 mutations confer an extremely slow growth phenotype when combined with the cla4 mutation, which causes defects in cytokinesis (Benton et al. 1993; Cvrcková et al. 1995), thus suggesting that Gicl and Gic2 may play a redundant and normally dispensable role in cytokinesis. Consistent with this idea, gicl gic2 cla4 mutant cells have a more severe cytokinesis defect than that of cla4 cells (G. Chen and C. Chan, unpubl.).

Cdc42 is present at the incipient bud site of unbudded cells, at the bud tip of budded cells, and at the motherbud neck at the time of cytokinesis (Ziman et al. 1993; E. $\mathrm{Bi}$, pers. comm.). In spite of the partial overlap in the localization pattern of GFP-Gicl and Cdc42, the localization of GFP-Gicl to the sites described above is largely independent of its ability to associate with Cdc42. Mutant GFP-Gic1 that cannot associate with Cdc42 is still found in the cortical patches, al beit at reduced levels, suggesting that $\mathrm{Cdc} 42$ is not absolutely required to direct GFP-Gic1 to these sites but instead may hel p to stabilize it at these locations. In this context, it is important to note that $\mathrm{Cdc} 42$ is not found at all cortical sites in which GFP-Gicl has been detected (e.g., at incipient bud sites in large-budded cells). In addition, mu- tant GFP-Gic1 that cannot bind Cdc42 still localizes to the mother-bud neck. This observation is not surprising because GFP-Gicl is found at this site rel atively early in the cell cycle (i.e., before onset of anaphase), whereas Cdc42 only localizes to this site at around the time of cytokinesis (Ziman et al. 1993; E. Bi, pers. comm.). Although mutant GFP-Gicl that cannot associate with Cdc42 appears to be properly localized in many cells, it is only partial ly functional, as it can complement only partially the $\mathrm{Ts}^{-}$phenotype of gicl gic2 mutant cells, indicating that the association between Cdc42 and Gicl is functionally important.

In addition to cortical sites and the mother-bud neck, GFP-Gicl is al so somewhat concentrated in the nucleus. This is especially obvious for mutant forms of GFP-Gic1 that cannot associate with $\mathrm{Cdc} 42$. Although the function of GFP-Gicl (and presumably Gicl) in the nucleus is unknown, this observation raises the intriguing possibility that Gicl may shuttle between the nucleus and the cell cortex, where Cdc42 is concentrated, thus transducing signals between these sites. WASP, a human CRIB motif-containing protein that binds $\mathrm{Cdc} 42$, has al so been detected both in the cytoplasm and within the nucleus (Symons et al. 1996).

\section{Relationship between Bem2 and Cdc42}

The carboxy-terminal 201-residue segment of Bem2 functions in vitro as a GAP for the Rhol but not the Cdc42 Rho-type GT Pase (Zheng et al. 1993, 1994; Peterson et al. 1994), thus suggesting that Bem2 functions in vivo as a regulator of Rhol. However, the Sac7 protein has been shown recently to function in vivo as a GAP for Rhol (Schmidt et al. 1997). The mutant phenotype caused by inactivation of Tor2, a positive regulator of Rhol, can be suppressed by the sac7 mutation, but not by the bem 2 mutation; and the phenotype of sac7 mutant cells can be suppressed by increased dosage of the SAC7 homolog BAG7, but not BEM2 (Schmidt et al. 1997). Furthermore, the phenotype of bem 2 mutant cells is suppressed partially, rather than exacerbated, by the sac7 mutation (G. Chen and C. Chan, unpubl.). These results suggest that Sac7 (and Bag7), and not Bem2, may be the major GAP for Rhol in vivo.

What then is the major in vivo function of Bem2? Several lines of evidence point toward a positive role of Bem2 in the function of $\mathrm{Cdc} 42$, or in the function of a protein whose function overlaps that of $\mathrm{Cdc} 42$. First, the phenotype of bem2 mutants is similar to that of cdc42 mutants (see introductory section). Second, increased dosage of MSB1 suppresses the phenotype of cdc42 as well as bem2 mutants (Bender and Pringle 1989, 1991). Third, the phenotype of bem2 mutant cells is exacerbated by loss-of-function mutations in BEM 3 or RGA1 (DBM 1) (Chen et al. 1996) and is suppressed by increased dosage of BEM3 (Bender and Pringle 1991). BEM3 and RGA1 encode GAPs for Cdc42 (Zheng et al. 1994; Stevenson et al. 1995). Fourth, the phenotype of bem2 mutant cells is suppressed by increased dosage of GIC 1 and GIC2, which encode putative effectors of Cdc42 
(this study). One possible interpretation of these results is that Bem2 functions in vivo as a GAP for $\mathrm{Cdc} 42$, and that cycling between the GTP- and GDP-bound states is important for some aspects of Cdc42 function. However, we have not been able to detect physical association between the GAP domain of Bem2 and GTP- or GDPbound forms of Cdc42 in the two-hybrid assay (G. Chen and C. Chan, unpubl.). Furthermore, increased dosage of CDC42 fails to suppress the phenotype of bem2 cells (Kim et al. 1994). Thus, details of the functional relationship between Bem2 and Cdc42 remain to be determined.

\section{Materials and Methods}

Strains, media, and genetic techniques

The yeast strains used in this study are listed in Table 1 . The diploid strain CBY 1830-51 was constructed by a one-step gene disruption procedure (Rothstein 1983), replacing one of the two GIC1 genes in DBY 1830 with the gic1- $\Delta 1:$ LEU 2 allele present on the $4.4-\mathrm{kb}$ Xhol-Sacl fragment of pCC878. The diploid strains CBY 1830-51-1 and CBY 1830-51-2 were similarly constructed, replacing one of the two GIC2 genes in CBY 1830-51 with the gic2-1::HIS3 allele present on the $\sim 4.2-\mathrm{kb}$ Pvull fragment of pCC968 and with the gic2- $22:: T R P 1$ allele present on the $\sim 2.6-\mathrm{kb}$ Kpnl-Sacl fragment of pCC998, respectively. The strain CBY 1830-51-1-1 was constructed by replacing one of the two CLA4 genes in CBY 1830-51-1 with the cla4- $101:: U$ RA3 allele present on the $2.5-\mathrm{kb}$ EcoRI-Xbal fragment of pCC 1077 . These gene disruptions were confirmed by DN A hybridization. The Escherichia coli strain DB1142 (leu pro thr hsdR hsdM recA) was used routinely as a host for plasmids.

Y east genetic manipulations as well as the preparation of rich medium (YEPD), synthetic minimal medium (SD), and SD with necessary supplements were performed as described (Rose et al. 1990). Quantitative mating assay was carried out according to established procedures (Sprague 1991). Two-hybrid assay was carried out essentially as described (Finley and Brent 1994).

Table 1. Yeast strains used in this study

\begin{tabular}{|c|c|c|}
\hline Strain & & Genotype \\
\hline DBY 1830 & $\mathbf{a} / \alpha$ & ade2/+lys2-801/+his3- $\Delta$ 200/his3- $\Delta 200$ ura3-52/ura3-52 leu2-3,112/leu2-3,112 trp1-1/trp1-1 \\
\hline CBY 1830-51 & $\mathbf{a} / \alpha$ & $\begin{array}{l}\text { ade2/+lys2-801/+his3- } \Delta 200 / \text { his3- } \Delta 200 \text { ura3-52/ura3-52 leu2-3,112/leu2-3,112 trp1-1/trp1-1 } \\
\text { gic1- } \Delta 1:: \text { LEU } 2 /+\end{array}$ \\
\hline CBY 1830-51-1 & $\mathbf{a} / \alpha$ & $\begin{array}{l}\text { ade2/+lys2-801/+ his3- } \Delta 200 / \text { his3- } \Delta 200 \text { ura3-52/ura3-52 leu2-3,112/leu2-3,112 trp1-1/trp1-1 } \\
\text { gic1- } \Delta 1:: \text { LEU 2/+ gic2-1::HIS3/+ }\end{array}$ \\
\hline CBY 1830-51-2 & $\mathbf{a} / \alpha$ & $\begin{array}{l}\text { ade2/+lys2-801/ + his3- } \Delta 200 / \text { his3- } \Delta 200 \text { ura3-52/ura3-52 leu2-3,112/leu2-3,112 trp1-1/trp1-1 } \\
\text { gic1- } \Delta 1:: \text { LEU 2/+ gic2- } \Delta 2:: T R P 1 /+\end{array}$ \\
\hline CBY 1830-51-1-1 & $\mathbf{a} / \alpha$ & $\begin{array}{l}\text { ade2/+ lys2-801/+his3- } \Delta 200 / \text { his3- } \Delta 200 \text { ura3-52/ura3-52 leu2-3,112/leu2-3,112 trp1-1/trp1-1 } \\
\text { gic1- } \Delta 1:: \text { LEU } 2 /+ \text { gic2-1::HIS3/+ cla4- } \Delta 101:: \text { U RA3/+ }\end{array}$ \\
\hline RFY 206 & a & lys2 $\Delta 201$ his3- $\Delta 200$ ura3-52 leu2-3,112 trp1 $\Delta:$ :hisG \\
\hline EGY 48 & $\alpha$ & his3 ura3-52 trp1 leu2::3Lexop-LEU 2 \\
\hline CCY 71-9C-1 & $\alpha$ & lys2-801 his3- $\Delta 200$ ura3-52 bem2-101 \\
\hline CCY311-17A & $\mathbf{a}$ & his3- $\Delta 200$ ura3-52 leu2-3,112 trp1-1 \\
\hline CCY 404-2D & $\mathbf{a}$ & Iys2-801 his3- $\Delta 200$ ura3-52 leu2-3,112 trp1-1 bud5::U RA3 \\
\hline CCY 441-52D & $\alpha$ & his3- $\Delta 200$ ura3-52 leu2-3,112 trp1-1 \\
\hline CCY 766-9D & $\mathbf{a}$ & Iys2-801 his3- $\Delta 200$ ura3-52 leu2-3,112 trp1-1 \\
\hline CCY 896-8B & $\mathbf{a}$ & his3- $\Delta 200$ ura3-52 leu2-3,112 cdc42-1 \\
\hline CCY 1024-19C & $\alpha$ & his3- $\Delta 200$ ura3-52 leu2-3,112 trp1-1 gic1- $\Delta 1::$ LEU 2 gic2-1::HIS3 \\
\hline CCY 1027-6A & $\mathbf{a}$ & his3- $\Delta 200$ ura3-52 leu2-3,112 cdc42-1 gic2-1::HIS3 \\
\hline CCY 1027-11D & $\mathbf{a}$ & his3- $\Delta 200$ ura3-52 leu2-3,112 cdc42-1 gic1- $\Delta 1:$ LEU 2 gic2-1::HIS3 \\
\hline CCY 1027-24A & $\mathbf{a}$ & his3- $\Delta 200$ ura3-52 leu2-3,112 cdc42-1 gic1- $\Delta 1:$ :LEU 2 \\
\hline CCY 1030-6D & $\mathbf{a}$ & his3- $\Delta 200$ ura3-52 leu2-3,112 trp1-1 bem2- $\Delta 110:: T R P 1$ gic2-1::HIS3 \\
\hline CCY $1030-10 C$ & $\mathbf{a}$ & his3- $\Delta 200$ ura3-52 leu2-3,112 trp1-1 bem2- $\Delta 110:: T R P 1$ gic1- $\Delta 1:$ LEU 2 \\
\hline CCY 1030-11B & $\alpha$ & his3- $\Delta 200$ ura3-52 leu2-3,112 trp1-1 bem2- $\Delta 110:: T R P 1$ \\
\hline CCY 1030-28D & $\mathbf{a}$ & his3- $\Delta 200$ ura3-52 leu2-3,112 trp1-1 bem2- $\Delta 110:: T R P 1$ gic1- $\Delta 1:$ LEU 2 gic2-1::HIS3 \\
\hline CCY 1032-2B & $\mathbf{a}$ & his3- $\Delta 200$ ura3-52 leu2-3,112 cdc24-2 gic1- $\Delta 1:: L E U ~ 2$ gic2-1::HIS3 \\
\hline CCY 1032-3A & $\mathbf{a}$ & his3- $\Delta 200$ ura3-52 leu2-3,112 cdc24-2 gic2-1::HIS3 \\
\hline CCY 1032-6B & $\mathbf{a}$ & his3- $\Delta 200$ ura3-52 leu2-3,112 cdc24-2 gic1- $\Delta 1:$ LEU 2 \\
\hline CCY 1032-16B & $\alpha$ & his3- $\Delta 200$ ura3-52 leu2-3,112 cdc24-2 \\
\hline CCY 1033-5A & $\mathbf{a}$ & his3- $\Delta 200$ ura3-52 leu2-3,112 trp1-1 gic2-1::HIS3 \\
\hline CCY 1033-5D & $\mathbf{a}$ & his3- $\Delta 200$ ura3-52 leu2-3,112 trp1-1 gic1- $\Delta 1::$ LEU 2 gic2-1::HIS3 \\
\hline CCY 1033-11B & $\mathbf{a}$ & his3- $\Delta 200$ ura3-52 leu2-3,112 trp1-1 gic1- $\Delta 1::$ LEU 2 \\
\hline CCY 1048-11A & $\mathbf{a}$ & Iys2-801 his3- $\Delta 200$ ura3-52 leu2-3,112 trp1-1 bud3- $\Delta 101::$ LEU 2 \\
\hline CCY 1055-4C & $\mathbf{a}$ & ade2 his3- $\Delta 200$ ura3-52 leu2-3,112 trp1-1 gic1- $\Delta 1:$ LEU 2 gic2-1::HIS3 cla4- $\Delta 101:: U$ RA3 \\
\hline CCY 1055-12B & $\mathbf{a}$ & ade2 his3- $\Delta 200$ ura3-52 leu2-3,112 trp1-1 gic2-1::HIS3 cla4- $\Delta 101:: U$ RA3 \\
\hline CCY 1055-16C & $\mathbf{a}$ & ade2 his3- $\Delta 200$ ura3-52 leu2-3,112 trp1-1 gic1- $\Delta 1:$ LEU 2 cla4- $\Delta 101:: U$ RA3 \\
\hline CCY 1056-6A & $\mathbf{a}$ & ade2 his3- $\Delta 200$ ura3-52 leu2-3,112 trp1-1 cla4- $\Delta 101::$ UA3 \\
\hline
\end{tabular}

Most of the yeast strains were constructed specifically for this study, the exceptions being DBY 1830, which is from D. Botstein's laboratory collection (Stanford University, Palo Alto, CA), and EGY 48 and RFY206, which are from R. Brent's laboratory collection (Harvard Medical School, Boston, MA). 
Isolation of GIC1 and GIC2

bem2-101 ura3-52 mutant yeast cells (CCY 71-9C-1) were transformed with a yeast genomic library constructed in the high copy number URA3 plasmid YEp24 (Carlson and Botstein 1982). U $\mathrm{ra}^{+}$transformants were selected by plating cells on supplemented SD lacking uracil. After $24 \mathrm{hr}$ at $26^{\circ} \mathrm{C}$, plates containing $\mathrm{U} \mathrm{ra}^{+}$transformants were shifted to $37^{\circ} \mathrm{C}$. After 3 more days, $\mathrm{Ts}^{+} \mathrm{U} \mathrm{ra}^{+}$transformants were identified and plasmids were recovered into $\mathrm{E}$. coli from such transformants. The ability of these plasmids to complement the Ts $\mathrm{s}^{-}$phenotype of bem2101 mutant at 35 or $37^{\circ} \mathrm{C}$ was retested. Of $\sim 22,000 \mathrm{U} \mathrm{ra}^{+}$transformants screened, four classes of plasmids were identified. One class (of 19 plasmids) contained, as expected, the BEM 2 gene. Another class, represented by the single GIC1 plasmid pCC 391, could complement the Ts $\mathrm{s}^{-}$phenotype of bem2-101 mutant efficiently at $35^{\circ} \mathrm{C}$ and very weakly at $37^{\circ} \mathrm{C}$.

The GIC2 gene was subcloned from cosmid 9740 (gift of $M$. Johnston, Washington University, St. Louis, MO), using available DNA sequence information of the GIC2 region.

\section{DNA manipulation}

pCC878, carrying the gic1- $\Delta 1::$ LEU 2 mutant allele, was constructed by replacing the DNA sequence between the BamHI and Sphl sites present in the low copy number URA3 plasmid pCC843 with the $2-\mathrm{kb}$ BamHI-Sphl fragment (containing LEU 2) of pJJ283 (Jones and Prakash 1990). pCC 968, carrying the gic2-1::HIS3 mutant allele, was constructed by inserting the $\sim 1.7-\mathrm{kb}$ BamHI fragment (containing HIS3) of pJJ215 (Jones and Prakash 1990) into the unique BamHI site of the low copy number URA3 plasmid pCC966. pCC998, carrying the gic2$\Delta 2:: T R P 1$ mutant allele, was constructed by replacing the DNA sequence between the BamHI and Pstl sites present in the pCC 966-derived low copy number TRP1 plasmid pCC 997 with the $\sim 0.8-k b$ BamHI-Pstl fragment (containing TRP1) of pJJ281 (Jones and Prakash 1990). The CLA 4 gene was amplified by PCR from genomic DNA of yeast strain S288C, using CLA4.1p and CLA 4.2p as primers (all primers used are listed in Table 2 ). The 3.6-kb BglII-EcoRI fragment derived from the PCR product was cloned into the BamHI-EcoRI sites of pU C 19 and PSM 217, thus generating $\mathrm{pCC} 1075$ and $\mathrm{pCC} 1079$, respectively. pCC1077, carrying the cla4- $\triangle 101:: U$ RA 3 mutant allele, was constructed by replacing the DNA sequence between the Xhol sites present in pCC1075 with the $\sim 1.1-\mathrm{kb}$ HindIII fragment (containing U RA3) of pJJ244 (Jones and Prakash 1990).

Plasmids used in two-hybrid assays were constructed as follows. For pCC984, which encodes AD-Gicl, a PCR reaction was carried out with pCC904 as template and MIP23.1p and MIP23.2p as primers. The $0.9-k b$ EcoRI-Xhol fragment derived from the PCR product was cloned into the EcoRI-Xhol sites of pJG4-5 (Gyuris et al. 1993). pCC985, which encodes AD-Gic2, was similarly constructed, using pCC967 as template and MIP23H.1p and MIP23H.2p as primers. The $1.1-\mathrm{kb}$ EcoRI fragment derived from the PCR product was cloned into the EcoRI site of pJG4-5. For pCC1044-1, which encodes AD-Gic1-2, a two-step recombinant PCR procedure was used (Horton et al. 1993). In the first step, two separate PCR reactions were carried out with pCC 904 as template, using the primers MIP23.1p and MIP23.4p in one reaction, and the primers MIP23.2p and MIP23.3p in the other reaction. In the second step, a PCR reaction was carried out with the two PCR products from the first step as templates, using the primers MIP23.1p and MIP23.2p. The $0.9-k b$ EcoRI-Xhol fragment derived from the final PCR product was cloned into the EcoRI-Xhol sites of pJG4-5. pCC1066-1, which encodes AD-Gic1- $\Delta 4$, was similarly constructed, except that the primers MIP23.3p and MIP23.4p were replaced by the primers MIP23.11p and MIP23.12p, respectively. pCC1050-1, which encodes AD-Gic1-3, was similarly constructed, except that pCC1043-2 was used as template for the first PCR step, and the primers MIP23.3p and MIP23.4p were replaced by the primers MIP23.8p and MIP23.9p, respectively. pCC1081-2, which encodes LexA-Cdc42 ${ }^{\top 35 A, C 1885}$, was also constructed by a two-step recombinant PCR procedure. In the first step, pEG202-CDC $42^{\text {C188S }}$ (Simon et al. 1995) was used as template and the primers lexA.1p and CDC42.5p were used in one reaction and the primers CDC $42.3 p$ and CDC $42.4 p$ were

Table 2. Primers used for PCR

\begin{tabular}{|c|c|}
\hline Primer & Sequence $\left(5^{\prime} \rightarrow 3^{\prime}\right)^{a}$ \\
\hline CDC42.3p & GATCGGATCCCTCGAGCTACAAAATTGTAGA \\
\hline CDC 42.4p & CAGCCGACTATGTTCCAGCAGTGTTCGA \\
\hline CDC $42.5 p$ & TAGTTATCGAACACTGCTGGAACATAG \\
\hline CLA4.1p & GGCGCACGAGGATAGTTC \\
\hline CLA 4.2p & GATCGAATTCGAACCATCCCAGTATCTC \\
\hline $\begin{array}{l}\text { lexA.1p } \\
\text { MIP23.1p }\end{array}$ & $\begin{array}{l}\text { GATTCGTCTGTTGCAGGAAG } \\
\text { ATGCGGATCCGAATTCATGACTGAAGGAAAGAGG }\end{array}$ \\
\hline MIP23.2p & AGCCAAGCTTCTCGAGTCAGGTATTTCGAGGAGTA \\
\hline MIP23.3p & CCATTTGATTTTCACGCTATTTCGGCTGCTAATGGT \\
\hline MIP23.4p & ССTTTTACCATTAGCAGCCGAAATAGCGTGAAAATC \\
\hline MIP23.8p & CGCAAAACAGTCAAGTGCAGCTACACCATTTG \\
\hline MIP23.9p & $\underline{\text { GAAAATCAAAT GGT GTAGCTGCACTTGACT GT }}$ \\
\hline MIP23.11p & CCAAAACCGCAAAACAGTCAAGT- GCTAATGGTAAAAGGGAAGAC \\
\hline MIP23.12p & GTCTTCCCTTTTACCATTAGC- ACTTGACTGTTTTGCGGTTTTGG \\
\hline MIP23H.1p & AGCCAGATCTGAATTCATGACTAGTGCAAGTATTAC \\
\hline MIP23H.2p & GCATTCTAGAGAATTCTTAAGTTTGCAGGGGCTCG \\
\hline
\end{tabular}

aSequences derived from yeast are underlined. Restriction enzyme recognition sequences are in italics. Yeast sequences missing from primers are denoted by dashes. 
used in another reaction. In the second step, the two PCR products from step one were used as templates and lexA.1p and CDC 42.3p were used as primers. The $\sim 0.6-\mathrm{kb}$ EcoRI-BamHI fragment derived from the final PCR product was cloned into the EcoRI-BamHI sites of pEG202.

Plasmids encoding GFP fusion proteins were constructed as follows. For pCC 995, which encodes GFP-Gicl, a PCR reaction was carried out with pCC904 as template and MIP23.1p and MIP23.2p as primers. The $\sim 0.9-\mathrm{kb}$ BamHI-HindlII fragment derived from the PCR product was cloned into the BamHI-HindlII sites of pRB2138 (Doyle and Botstein 1996). pCC 1065-1, which encodes GFP-Gic2, was similarly constructed, using pCC 967 as template and MIP23H.1p and MIP23H.2p as primers. The $1.1-$ $\mathrm{kb}$ BgllI-Xbal fragment derived from the PCR product was cloned into the BamHI-Xbal sites of pRB2138. pCC1043-2, which encodes GFP-Gic1-2, pCC1051-1, which encodes GFPGic1-3, and pCC1067-1, which encodes GFP-Gic1- $\Delta 4$, were constructed as described for pCC1044-1, pCC1050-1, and pCC1066-1, respectively, except that the $\sim 0.9-\mathrm{kb}$ BamHIHindIII fragment derived from the final PCR product in each case was cloned into the BamHI-HindlII sites of pRB2138.

\section{Cytological techniques}

Live yeast cells grown at room temperature $\left(24^{\circ} \mathrm{C}\right)$ were used for observation of GFP fusion proteins. In experiments in which visualization of DNA was desired, 4',6-diamidino-2-phenylindole (DAPI; Accurate Chemical Co., Westbury, NY) was added to the growth medium to a final concentration of $2.5 \mu \mathrm{g} / \mathrm{ml} \sim 30$ min before observation of cells. Immunofluorescence staining of yeast cells was carried out as described (Pringle et al. 1989).

\section{Acknowledgments}

We thank Jon Mulholland, Erfei Bi, Claudio De Virgilio, Mark Johnston, DougJohnson, Elaine Elion, and Humberto M artin for the supply of strains, antibodies, and plasmids, and Brian Haarer for comments on the manuscript. This work was supported by National Institutes of Health grant GM45185 and Advanced Research Program grant 003658-510 from The Texas Higher Education Coordinating Board.

The publication costs of this article were defrayed in part by payment of page charges. This article must therefore be hereby marked "advertisement" in accordance with 18 USC section 1734 solely to indicate this fact.

\section{Note added in proof}

The GIC1 and GIC2 genes have been characterized independently in the laboratories of J. Chant and M. Peter (Brown et al., this issue).

\section{References}

Adams, A.E.M . and J.R. Pringle. 1984. Relationship of actin and tubulin distribution in wild-type and morphogenetic mutant Saccharomyces cerevisiae. J. Cell Biol. 98: 934-945.

Adams, A.E.M., D.I. Johnson, R.M. Longnecker, B.F. Sloat, and J.R. Pringle. 1990. CDC42 and CDC 43, two additional genes involved in budding and the establishment of cell polarity in the yeast Saccharomyces cerevisiae. J. Cell Biol. 111: 131142.

Amberg, D.C., J.E. Zahner, J.W. Mulholland, J.R. Pringle, and D. Botstein. 1997. Aip3p/Bud6p, a yeast actin-interacting protein that is involved in morphogenesis and the selection of bipolar budding sites. Mol. Biol. Cell 8: 729-753.

Ayscough, K.R., J. Stryker, N. Pokala, M. Sanders, P. Crews, and D.G. Drubin. 1997. High rates of actin filament turnover in budding yeast and roles for actin in establishment and maintenance of cell polarity revealed using the actin inhibitor latrunculin-A. J. Cell Biol. 137: 399-416.

Bender A. and J.R. Pringle. 1989. Multicopy suppression of the cdc24 budding defect in yeast by CDC42 and three newly identified genes including the ras-related gene RSR1. Proc. Natl. Acad. Sci. 86: 9976-9980.

-_- 1991. U se of a screen for synthetic lethal and multicopy suppressee mutants to identify two new genes involved in morphogenesis in Saccharomyces cerevisiae. Mol. Cell. Biol. 11: 1295-1305.

Bender, L., H.S. Lo, H. Lee, V. Kokojan, J. Peterson, and A. Bender. 1996. Associations among PH and SH 3 domain-containing proteins and Rho-type GTPases in yeast. J. Cell Biol . 133: 879-894.

Benton, B.K., A.H. Tinkel enberg, D. Jean, S.D. Plump, and F.R. Cross. 1993. Genetic analysis of CIn/Cdc28 regulation of cell morphogenesis in budding yeast. EMBO J. 12: 5267-5275.

Bi, E. and J.R. Pringle. 1996. ZDS1 and ZDS2, genes whose products may regulate $C d c 42 p$ in Saccharomyces cerevisiae. Mol. Cell. Biol. 16: 5264-5275.

Brown, J.L., M. Jaquenoud, M.-P. Gulli, J. Chant, and M. Peter. 1997. N ovel Cdc42-binding proteins Gic1 and Gic2 control cell polarity in yeast. Genes \& Dev. (this issue).

Burbel o, P.D., D. Drechsel, and A. Hall. 1995. A conserved binding motif defines numerous candidate target proteins for both Cdc42 and Rac GTPases. J. Biol. Chem. 270: 2907129074.

Carlson, M. and D. Botstein. 1982. Two differentially regulated mRN As with different $5^{\prime}$ ends encode secreted and intracellular forms of yeast invertase. Cell 28: 145-154.

Chan, C.S.M. and D. Botstein. 1993. Isolation and characterization of chromosome-gain and increase-in-ploidy mutants in yeast. Genetics 135: 677-691.

Chant, J. and I. Herskowitz. 1991. Genetic control of bud site selection in yeast by a set of gene products tht constitute a morphogenetic pathway. Cell 65: 1203-1212.

Chant, J. and J.R. Pringle. 1995. Patterns of bud-site selection in the yeast Saccharomyces cerevisiae. J. Cell Biol. 129: 751765.

Chant, J., K. Corrado, J.R. Pringle, and I. Herskowitz. 1991. Yeast BUD5, encoding a putative GDP-GTP exchange factor, is necessary for bud site sel ection and interacts with bud formation gene BEM 1. Cell 65: 1213-1224.

Chant, J., M. Mischke, E. Mitchell, I. Herskowitz, and J.R. Pringle. 1995. Role of Bud3p in producing the axial budding pattern of yeast. J. Cell Biol. 129: 767-778.

Chen, G.-C., L. Zheng, and C.S.M. Chan. 1996. The LIM domain-containing Dbml GTPase-activating protein is required for normal cellular morphogenesis in Saccharomyces cerevisiae. Mol. Cell. Biol. 16: 1376-1390.

Cvrcková, F., C. De Virgilio, E. Manser, J.R. Pringle, and K. N asmyth. 1995. Ste20-like protein kinases are required for normal localization of cell growth and for cytokinesis in budding yeast. Genes \& Dev. 9: 1817-1830.

Doyle, T. and D. Botstein. 1996. Movement of yeast cortical actin cytoskel eton visualized in vivo. Proc. Natl. Acad. Sci. 93: 3886-3891.

Evangelista, M., K. Blundell, M.S. Longtine, C.J. Chow, N A dames, J.R. Pringle, M. Peter, and C. Boone. 1997. Bni 1p, a yeast formin linking $\mathrm{Cdc} 42 \mathrm{p}$ and the actin cytoskel eton during polarized morphogenesis. Science 276: 118-122. 
Finley, R.L. and R. Brent. 1994. Interaction mating reveals binary and ternary connections between Drosophila cell cycle regulators. Proc. Natl. Acad. Sci. 91: 12980-12984.

Gyuris, J., E. Golemis, H. Chertkov, and R. Brent. 1993. Cdi 1, a human $\mathrm{Gl}$ and $\mathrm{S}$ phase protein phosphatase that associates with Cdk2. Cell 75: 791-803.

Heim, R., A.B. Cubitt, and R.Y. Tsien. 1995. Improved green fluorescence. Nature 373: 663-664.

Horton, R.M., S.N. Ho, J.K. Pullen, H.D. Hunt, Z. Cai, and L.R. Pease. 1993. Gene splicing by overlap extension. Methods Enzymol. 217: 270-279.

Johnson, D.I. and J.R. Pringle. 1990. Molecular characterization of CDC42, a Saccharomyces cerevisiae gene involved in the development of cell polarity. J. Cell. Biol. 111: 143-152.

Jones, J.S. and L. Prakash. 1990. Y east Saccharomyces cerevisiae sel ectable markers in pU C18 polylinkers. Yeast 6: 363366.

Kilmartin, J. and A.E.M. Adams. 1984. Structural rearrangements of tubulin and actin diring the cell cycle of the yeast Saccharomyces. J. Cell Biol. 98: 922-933.

Kim, Y.-J., L. Francisco, G.-C. Chen, E. Marcotte, and C.S.M. Chan. 1994. Control of cellular morphogenesis by the Ipl2/ Bem2 GTPase-activating protein: Possible role of protein phosphorylation. J. Cell Biol. 127: 1381-1394.

Lew, D.J. and S.I. Reed. 1993. Morphogenesis in the yeast cell cycle: Regulation by $\mathrm{Cdc} 28$ and cyclins. J. Cell Biol. 120: 1305-1320.

Li, R., Y. Zheng, and D.G. Drubin. 1995. Regulation of cortical actin cytoskel eton assembly during polarized cell growth in budding yeast. J. Cell Biol. 128: 599-615.

Martin, H., A. Mendoza, J.M. Rodriguez-Pachón, M. Molina, and C. N ombela. 1997. Characterization of SKM 1, a Saccharomyces cerevisiae gene encoding a novel Ste20/PAK-like protein kinase. Mol. Microbiol. 23: 431-444.

Matsui, Y., R. M atsui, R. Akada, and A. Toh-e. 1996. Yeast src homology region 3 domain-binding proteins involved in bud formation. J. Cell Biol. 133: 865-878.

Park, H.-O., E. Bi, J.R. Pringle, and I. Herskowitz. 1997. Two active states of the Ras-related Bud1/Rsrl protein bind to different effectors to determine yeast cell polarity. Proc. Natl. Acad. Sci. 94: 4463-4468.

Peterson, J., Y. Zheng, L. Bender, A. Myers, R. Cerione, and A. Bender. 1994. Interactions between the bud emergence proteins Bem1p and Bem2p and Rho-type GTPases in yeast. J. Cell Biol. 127: 1395-1406.

Pringle, J.R., R.A. Preston, A. Adams, T. Stearns, D. Drubin, B.K. Haarer, and E. Jones. 1989. Fluorescence microscopy methods for yeast. Methods Cell Biol. 31: 357-435.

Roemer, T., L.G. Vallier, and M. Snyder. 1996. Selection of polarized growth sites in yeast. Trends Cell Biol. 6: 434-441.

Rose, M.D., F. Winston, and P. Hieter. 1990. Methods in yeast genetics. Cold Spring Harbor Laboratory Press, Cold Spring Harbor, NY.

Rothstein, R.J. 1983. One-step gene disruption in yeast. Methods Enzymol. 101: 202-211.

Ruggieri, R., A. Bender, Y. M atsui, S. Powers, Y. Takai, J.R. Pringle, and K. Matsumoto. 1992. RSR1, a ras-like gene homologous to Krev-1 (smg21A/rap1A): Role in the development of cell polarity and interactions with the Ras pathway in Saccharomyces cerevisiae. Mol. Cell. Biol. 12: 758-766.

Schmidt, A., M. Bickle, T. Beck, and M.N. Hall. 1997. The yeast phosphatidylinositol kinase homolog TOR2 activates RHO1 and RHO2 via the exchange factor ROM 2. Cell 88: 531-542.

Simon, M.-N ., C. De Virgilio, B. Souza, J.R. Pringle, A. Abo, and S.I. Reed. 1995. Role for the Rho-family GTPase Cdc42 in yeast mating-pheromone signal pathway. Nature 376: 702-
705

Sloat, B.F. and J.R. Pringle. 1978. A mutant of yeast defective in cellular morphogenesis. Science 200: 1171-1173.

Sloat, B.F., A. Adams, and J.R. Pringle. 1981. Roles of the CDC24 gene product in cellular morphogenesis during the Saccharomyces cerevisiae cell cycle. J. Cell Biol. 89: 395405.

Sprague, G.F. 1991. Assay of yeast mating reaction. Methods Enzymol. 194: 77-93.

Stevenson, B.J., B. Ferguson, C. De Virgilio, E. Bi, J.R. Pringle, G. Ammerer, and G.F. Sprague. 1995. Mutation of RGA1, which encodes a putative GTPase-activating protein for the polarity-establishment protein Cdc42p, activates the phermone response pathway in the yeast Saccharomyces cerevisiae. Genes \& Dev. 9: 2949-2963.

Sutton, A., D. Immanuel, and K.T. Arndt. 1991. The SIT4 protein phosphatase functions in late $\mathrm{G} 1$ for progression into $S$ phase. Mol. Cell. Biol. 11: 2133-2148.

Symons, M., J.M.J. Derry, B. Karlak, S. Jiang, V. Lemahieu, F. M cCormick, U. Francke, and A. Abo. 1996. Wiskott-Aldrich syndrome protein, a novel effector for the GTPase CDC42Hs, is implicated in actin polymerization. Cell 84: 723-734.

Wang, T. and A. Bretscher. 1995. The rho-GAP encoded by BEM2 regulates cytoskeletal structure in budding yeast. Mol. Biol. Cell. 6: 1011-1024.

Yamochi, W., K. Tanaka, H. N onaka, A. M aeda, T. M ucha, and Y. Takai. 1994. Growth site localization of Rhol small GTPbinding protein and its involvement in bud formation in Saccharomyces cerevisiae. J. Cell Biol. 125: 1077-1093.

Zahner, J.E., H.A. Harkins, and J.R. Pringle. 1996. Genetic analysis of the bipolar pattern of bud site selection in the yeast Saccharomyces cerevisiae. Mol. Cell. Biol. 16: 18571870.

Zhao, Z.-S., T. Leung, E. M anser, and L. Lim. 1995. Pheromone signaling in Saccharomyces cerevisiae requires the small GTP-binding protein Cdc42p and its activator CDC24. Mol. Cell. Biol. 15: 5246-5257.

Zheng, Y., M.J. Hart, K. Shinjo, T. Evans, A. Bender, and R.A. Cerione. 1993. Biochemical comparisons of the Saccharomyces cerevisiae Bem2 and Bem3 proteins. J. Biol. Chem 268: 24629-24634.

Zheng, Y., R. Cerione, and A. Bender. 1994. Control of the yeast bud-site assembly GTPase Cdc42: Catalysis of guaninenucleotide exchange by Cdc24 and stimulation of GTPase activity by Bem3. J. Biol. Chem. 269: 2369-2372.

Zheng, Y., A. Bender, and R.A. Cerione. 1995. Interaction among proteins involved in bud-site assembly in Saccharomyces cerevisiae. J. Biol. Chem. 270: 626-630.

Ziman, M. and D.I. Johnson. 1994. Genetic evidence for a functional interaction between Saccaromyces cerevisiae CDC24 and CDC42. Yeast 10: 463-474.

Ziman, M., J.M. O'Brien, L.A. Ouellette, W.R. Church, and D.I. Johnson. 1991. Mutational analysis of CDC42Sc, a Saccharomyces cerevisiae gene that encodes a putative GTP-binding protein involved in the control of cell polarity. Mol. Cell. Biol. 11: 3537-3544.

Ziman, M., D. Preuss, J. Mulholland, J.M. O’Brien, D. Botstein, and D.I. Johnson. 1993. Subcellular local ization of Cdc42p, a Saccharomyces cerevisiae GTP-binding protein involved in the control of cell polarity. Mol. Biol. Cell 4: 1307-1316. 


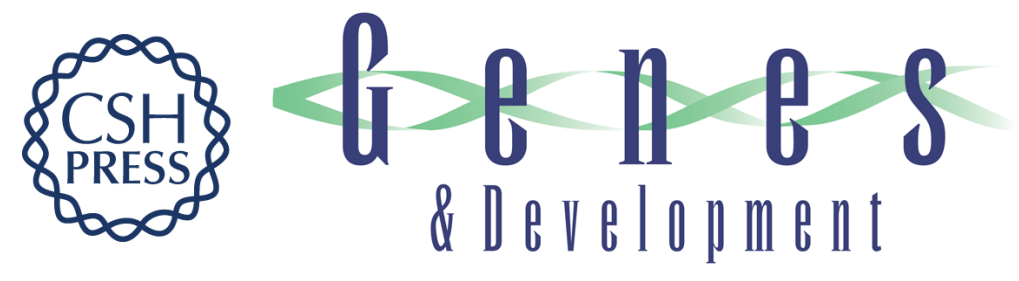

\section{The Cdc42 GTPase-associated proteins Gic1 and Gic2 are required for polarized cell growth in Saccharomyces cerevisiae}

Guang-Chao Chen, Yung-Jin Kim and Clarence S.M. Chan

Genes Dev. 1997, 11:

Access the most recent version at doi:10.1101/gad.11.22.2958

References This article cites 55 articles, 39 of which can be accessed free at: http://genesdev.cshlp.org/content/11/22/2958.full.html\#ref-list-1

License

Email Alerting

Receive free email alerts when new articles cite this article - sign up in the box at the top Service right corner of the article or click here.

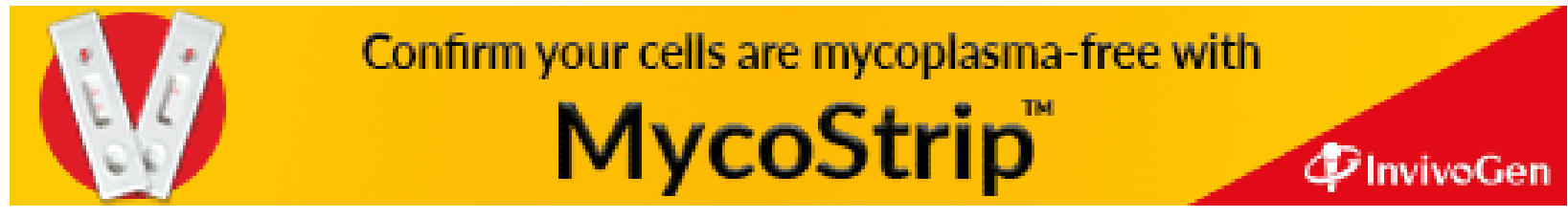

